\author{
Maestría en Economía \\ Facultad de Ciencias Económicas \\ Universidad Nacional de La Plata
}

TESIS DE MAESTRIA

\begin{abstract}
ALUMNO
Matías Italia

TITULO

Efectos de un Accidente Ferroviario sobre la Demanda del Servicio: El Caso de la Tragedia de Once en Argentina

DIRECTOR

María Laura Alzúa

FECHA DE DEFENSA

$10 / 30 / 2018$
\end{abstract}




\title{
Efectos de un accidente ferroviario sobre la demanda del servicio: el caso de la tragedia de Once en Argentina*
}

\author{
Matías Italia ${ }^{\dagger}$ \\ Noviembre, 2018
}

\section{Resumen:}

Este trabajo evalúa el impacto de un accidente ferroviario, conocido como la "Tragedia de Once", sobre la demanda de viajes del servicio afectado en Argentina. Debido a que el accidente no puede considerarse como un shock exógeno, para identificar el efecto causal de la tragedia se utiliza la metodología de Control Sintético. Específicamente se considera una combinación de diferentes ramales para construir un control sintético que simule en características relevantes el ramal afectado, antes de que sucediera el accidente. Los resultados indican que para los dos años posteriores al accidente la evolución de los boletos vendidos por tren corrido es en promedio entre 53pp y 59pp menor que el control sintético. El efecto identificado comienza a reducirse a partir de 19 meses luego del accidente, hasta desaparecer luego de 28 meses. Además, debido a que el ramal afectado pudo haber sufrido una reducción en el pago del boleto, al utilizar como grupo de control ramales más comparables en términos de evasión, se encuentra que el efecto se reduce a $-21 \mathrm{pp}$. Este trabajo se destaca por su aporte original a la literatura, ya que a la fecha no se han encontrado antecedentes sobre evaluaciones de impacto vinculadas a accidentes ferroviarios en Argentina.

\begin{abstract}
:
This paper assess the impact of a railway accident, known as "Tragedia de Once", on the demand of the affected service in Argentina. Given that the accident cannot be considered as an exogenous shock, to identify the causal effect of the event we use the Synthetic Control method. We use a combination of different railways to construct a synthetic control that mirrors relevant features of the affected railway before the accident. We find that our constructed ticket sold index, adjusted for the numbers of trains run, decline, on average, between 53pp and 59pp for the two years after de accident. However, this effect start to reduce from 19 months after the accident, to finally disappear after 28 months. Furthermore, as the affected railway could have suffered a reduction in the tickets' payment, using a more comparable control group in terms of evasion the effect reduces to $-21 \mathrm{pp}$. The contribution of this research is the originality of the topic, as we found no evidence of prior research regarding impact evaluations related to railway accident in Argentina.
\end{abstract}

Códigos JEL: R41, C5, C1

\footnotetext{
*Este trabajo constituye mi tesis de Maestría en Economía de la UNLP, realizada bajo la dirección de María Laura Alzúa, a quien agradezco enormemente por todo su tiempo y apoyo a lo largo de este proceso. También agradezco los comentarios y sugerencias de Santiago Urbiztondo y Federico Juncosa, junto a todo el equipo de la Dirección de Investigación Socioeconómica de CAF. Además, este trabajo forma parte del proyecto Mejorando Capacidades en Evaluación de Impacto en América Latina del Centro de Estudios Distributivos, Laborales y Sociales (CEDLAS-UNLP), y cuenta con financiamiento del Centro Internacional de Investigaciones para el Desarrollo (IDRC-Canadá). Cualquier error u omisión es de mi exclusiva responsabilidad.
}

† UBA, UNLP, CAF. Email: matias italia@hotmail.com 


\section{Introducción}

Las ciudades de América Latina, a diferencia de las ciudades de países desarrollados, se caracterizan por una escasa e inadecuada infraestructura de movilidad, lo cual impacta sobre la disponibilidad y calidad de los medios de transporte urbano [CAF, 2017].

Entendiendo que la movilidad no es un fin en sí mismo sino un medio necesario para acceder a diferentes oportunidades, las personas toman decisiones sobre como trasladarse en función de las alternativas de transporte disponibles. Dicha decisión va a depender también de las características del viaje que tiene que realizar, los costos monetarios y otros atributos no monetarios, como por ejemplo la calidad del servicio. Vinculado a la calidad del viaje podemos resaltar la disponibilidad, accesibilidad, información, tiempo, servicio al cliente, comodidad, impacto ambiental y seguridad del servicio.

Con respecto a la evidencia de la literatura, son numerosos los trabajos que estudian los determinantes de la demanda de transporte público, pero reducidos los que incorporan atributos vinculados a la seguridad. Sin embargo, según los datos de la encuesta CAF (2016) para América Latina, en promedio el $28 \%$ de los usuarios resaltan aspectos vinculados a la seguridad como el principal problema que debe ser mejorado en el transporte público, tal como puede apreciarse el siguiente gráfico:

Gráfico 1. Principales aspectos a ser mejorados en el transporte público para América Latina

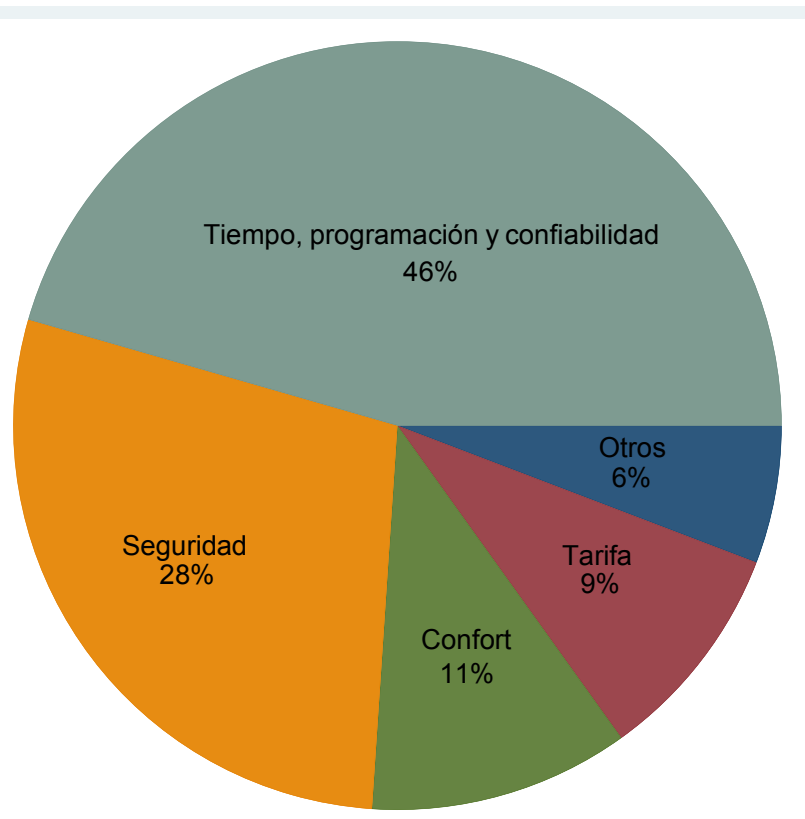

Nota: se presenta el porcentaje promedio de personas que señalaron cada aspecto como el principal a mejorar para las ciudades de Bogotá, Buenos Aires, Caracas, Ciudad de México, Ciudad de Panamá,

Fortaleza, La Paz, Lima, Montevideo, Quito y San Pablo. El aspecto de Seguridad incluye mejorar la seguridad vial, la seguridad en el vehículo y durante la espera en la parada o estación.

Fuente: Elaboración propia en base a la encuesta CAF 2016

El objetivo de este trabajo consiste en estimar cómo un shock sobre la percepción de seguridad de un servicio de transporte afecta la demanda del mismo. Para ello se estudia un accidente ferroviario en la Ciudad de Buenos Aires (Argentina) ocurrido en febrero de 2012, de gran difusión nacional. Este accidente, conocido como la tragedia de Once, fue provocado cuando una formación del ferrocarril Sarmiento (ramal Once - Moreno) de la empresa Trenes de Buenos Aires S.A. (TBA) no detuvo su marcha al ingresar en la estación Once de Septiembre y se estrelló contra el paragolpes del andén, dejando un saldo de 51 pasajeros fallecidos y más de 700 resultaron heridos [Müller, 2012; Despouy, 2014a]. Se convirtió en la tercera tragedia ferroviaria más grave del país, luego de los accidentes de Benavídez de 1970 donde murieron 236 personas, 
y el ocurrido en la localidad de Sa Pereira de 1978 donde fallecieron 55 personas [Despouy, 2014b]. ${ }^{1}$

Este accidente no fue un hecho aislado en el transporte ferroviario de la Región Metropolitana de Buenos Aires: el 13 de septiembre de 2011 un tren embistió a un colectivo y luego chocó con otra formación, ocasionando la muerte de 11 personas y dejando a 228 heridas. Este hecho es conocido como la Tragedia de Flores, sucedió cinco meses antes que la Tragedia de Once y la línea ferroviaria afectada también fue el ferrocarril Sarmiento.

Sin embargo, como distingue Barbero (2012), la Tragedia de Once puso a los ferrocarriles de la RMBA en la mira. La gravedad de los hechos llevó a que el Gobierno Nacional tomara dos medidas sustanciales:

1- el sistema de transporte pasó a depender del Ministerio de Planificación Federal, Inversión Pública y Servicios al nuevo Ministerio del Interior y Transporte;

2- se revocó la concesión de TBA por incumplimiento de contrato para las líneas Mitre y Sarmiento. Como destaca Despouy (2014a): "Para la gestión de estas líneas se debió crear la UGOMS (Unidad de Gestión Operativa Mitre Sarmiento), sociedad anónima compuesta por Ferrovías y Metrovías, que pasaron a estar a cargo del nivel operativo, mientras que el Estado quedó como responsable del pago de los salarios a través de la Administradora de Recursos Humanos Ferroviarios"2.

Ante este contexto, con el objetivo de estimar el efecto del accidente sobre la demanda se utiliza la metodología de Control Sintético desarrollada por Abadie y Gardeazabal (2003). Específicamente se considera una combinación de diferentes ramales para construir un control sintético que simule en características relevantes el ramal afectado, antes de que sucediera el accidente. Con información mensual a nivel ramal de ferrocarril para el periodo 2008-2015, se encuentra que para los dos años posteriores al accidente la evolución de los boletos vendidos por tren corrido es en promedio entre 53pp y 59pp menor que el control sintético. El efecto identificado comienza a reducirse a partir de 19 meses luego del accidente, hasta desaparecer luego de 28 meses. Además, debido a que el ramal afectado pudo haber sufrido una reducción en el pago del boleto, al utilizar como grupo de control ramales más comparables en términos de evasión, se encuentra que el efecto se reduce a $-21 \mathrm{pp}$.

Este trabajo se destaca por su aporte original a la literatura de demanda de transporte, ya que a la fecha no se han encontrado antecedentes sobre evaluaciones de impacto vinculadas a accidentes ferroviarios en Argentina.

En primer lugar se presentará una revisión de la literatura, destacando los trabajos más relevantes sobre la temática del trabajo. En segundo lugar se describirá el marco conceptual y la metodología de control sintético, resaltando los supuestos y limitaciones. En tercer lugar se describirán los datos utilizados, y con el objetivo de dimensionar la tragedia de Once se presentarán algunos gráficos y estadísticas descriptivas. En cuarto lugar se presentarán los resultados encontrados y por último se distinguen las conclusiones del trabajo.

\footnotetext{
1 El accidente sucedió en hora pico, a las 08:33 a.m. del día miércoles 22 de febrero de 2012.

2 Despouy, L. (2014a). "Transporte ferroviario: Informe sectorial del Presidente de la Auditoría General de la Nación. Una década al cuidado de los fondos públicos”. Auditoría General de la Nación. Buenos Aires. Pág. 22.
} 


\section{Revisión de literatura}

Es extensa la literatura que estudia los determinantes de la demanda de transporte. En función de la información disponible, y su nivel de desagregación, estiman los efectos de diferentes factores sobre la demanda del servicio, como ser tarifas, atributos sobre la calidad del servicio, contexto económico, etc.

Webster y Bly (1982), uno de los primeros trabajos vinculado a la demanda de transporte público, resaltan que a diferencia de las tarifas, el concepto de "calidad de servicio" cubre aspectos bastante distintos del transporte público. Los autores clasifican la calidad del servicio en tres categorías: 1) programación del servicio y red de transporte, 2) cumplimiento del cronograma publicado; 3) comodidad, conveniencia y seguridad del transporte público, tanto en los medios de transporte como en las paradas o estaciones.

Sin embargo, son reducidos los estudios que incorporan la seguridad en sus modelos de demanda.

Owen y Phillips (1987), utilizando series de tiempo estiman los efectos de diferentes factores económicos sobre la demanda de viajes en tren en Gran Bretaña, como por ejemplo el crecimiento del Producto Interno Bruto. Wardman (1994) propone un método para realizar proyecciones de demanda para Gran Bretaña en función de cambios en la calidad del servicio, como ser tiempo de viaje, frecuencia del servicio y cantidad de intercambios de transporte. FitzRoy y Smith (1998) analizan la demanda de ferrocarriles en 14 países de Europa, para el periodo 1968-1991, y además de información sobre las tarifas, los autores también incluyen la frecuencia de los trenes y densidad de vías de tren como variables sobre la calidad del servicio. Wardman (2006) estudia los efectos de diversos factores externos sobre la demanda de trenes en Gran Bretaña, como ser el crecimiento del PIB, tiempos de viajes en automóvil y los costos del combustible. Sartori (2003) estima las elasticidades precio, calidad del servicio e ingreso de la demanda de ómnibus en Córdoba (Argentina), utilizando datos de series temporales para el periodo 1993 - 2000.

Por otro lado, Evans y Morrison (1997) introducen el concepto de seguridad en un modelo económico de transporte público, incorporando el riesgo de accidente tanto en la función de costos de del operador como en la de los usuarios.

Vinculado a ello, las normas UNE-EN 13816 y 15140 de la Unión Europea están destinadas a ser utilizadas por los prestadores de servicios de transporte público con el objetivo de definir los requisitos básicos para la medición de calidad del servicio. En cuanto a los atributos que representan la calidad, estos pueden ser agrupados en ocho temáticas: disponibilidad, accesibilidad, información, tiempo, servicio al cliente, comodidad, impacto ambiental y seguridad [Dell'olio et al., 2018].

Además, en su guía práctica sobre la demanda de transporte público, Balcombe et al. (2004) resaltan el atributo de seguridad dentro de la calidad del servicio, entendiéndola como la presencia y disposición del personal frente a los pasajeros (abordo y en las estaciones).

Asimismo, Preston y Robins (2013) evalúan para Gran Bretaña los efectos de largo plazo de la privatización del transporte ferroviario de pasajeros sobre la demanda. Los autores incluyen una variable que indica el accidente de Hatfield, y encuentran un efecto negativo sobre la demanda del $5 \%$ entre los años 2000 y 2006.

Y es en este contexto donde se enmarca nuestro objetivo de estimar el efecto de la tragedia de Once sobre la demanda del servicio.

Vinculado a este objetivo podemos destacar el aporte de Wei et al. (2017), donde estudian la sustitución de trenes de alta velocidad por viajes aéreos a partir de dos shocks de demanda ocasionados por dos eventos: el lanzamiento de los ferrocarriles de alta velocidad en el tramo 
Beijing-Shanghai y el accidente ferroviario de Wenzhou ${ }^{3}$. Debido a que estos medios de transportes son substitutos, estiman los efectos sobre las tarifas de pasajes aéreos y encuentran que el accidente tuvo un efecto positivo y estadísticamente significativo del $27,6 \%$. Por otro lado, Wang et al. (2018) estiman el efecto de este accidente ferroviario sobre la demanda de pasajes aéreos, haciendo énfasis en que por lo menos en el corto plazo, el pánico y la pérdida de confianza producida por el accidente podría desviar la demanda de viajes de ferrocarriles a las aerolíneas. Sin embargo, el autor no encuentra un efecto estadísticamente significativo sobre la cantidad demandada de pasajes, pero resalta que esto puede deberse a que el efecto del accidente se atenuó en un período de tiempo corto, y como utiliza datos trimestrales no puede capturarlo con precisión.

A su vez, en Zotova (2017) se estudia el efecto del accidente del Vuelo 261 de Alaska Airlines sobre la demanda de los vuelos de la línea afectada, y considerando la cantidad de pasajeros encuentra una caída del $26 \%$ para el primer trimestre posterior al accidente. Ito y Lee (2005) evalúan el impacto del atentado del 11 de septiembre sobre la demanda de viajes aéreos en Estados Unidos. Con datos hasta noviembre de 2003, encuentran un efecto negativo (y estadísticamente significativo) de más del $30 \%$ sobre la demanda de corto plazo, y además encuentran que persistía una caída del $7,4 \%$, la cual no puede explicarse por factores económicos, de temporada u otros.

Por otro lado, vinculado a la seguridad en transporte podemos resaltar el trabajo de Cameron et al. (1993), donde evalúan los beneficios de las campañas de publicidad de televisión de la Comisión de Accidentes de Transporte en el estado de Victoria (Australia), como también el de Newstead y Cameron (2003), que analizan los efectos del programa de radares sobre los choques en el estado Queensland (Australia).

En referencia al análisis de los accidentes ferroviarios en Argentina podemos destacar el informe de Despouy (2014b) de la Auditoría General de la Nación, donde se examinan los casos de las tragedias de Once, Flores y Zanjitas. En dicho informe, con el fin de evitar que ocurran futuras catástrofes, se proponen recomendaciones específicas sobre el mantenimiento y la seguridad de los trenes. A su vez, en otro trabajo de Despouy (2014a) se examina el sistema ferroviario argentino a partir de las auditorías de la AGN sobre las redes ferroviarias del país en el periodo 2002-2012. Analizando la gestión del Estado en materia de transporte ferroviario, se concluye que en la última década no se revirtió el estado de deterioro en el que quedó el sector luego de las concesiones de las líneas ferroviarias a diferentes operadores privadas en los '90. En esta misma línea de trabajo, Barbero (2012) propone una política integral de transporte a partir de la tragedia de Once, donde incluye un plan de obras de inversión, un modelo de gestión de los servicios, un esquema de financiamiento y los ajustes correspondientes en la organización institucional del sector. Por otro lado, poniendo énfasis sobre la responsabilidad civil, el trabajo de Pirota (2009) analiza los accidentes ferroviarios en Argentina, y se enfoca en la responsabilidad de las empresas privatizadas y del Estado frente a los usuarios y terceros; mientras que González (2017) discute el carácter del error humano en el análisis de dos accidentes ferroviarios, uno de ellos la Tragedia de Once.

Como ya fue resaltado, este trabajo se destaca por el aporte original a la literatura de demanda de transporte, ya que a la fecha no se han encontrado antecedentes sobre evaluaciones de impacto vinculadas a accidentes ferroviarios en Argentina.

3 El 23 de julio de 2011, dos trenes de alta velocidad de la línea ferroviaria Yongtaiwen colisionaron en Wenzhou, ocasionando el fallecimiento de 40 personas y 192 resultaron heridas. 


\section{Metodología}

\subsection{Marco conceptual}

Consideremos un modelo de demanda donde existe un pasajero $h$ que desea realizar un determinado viaje, y para ello dispone de $z \in Z$ alternativas de transporte. Entendiendo que la movilidad no es un fin en sí mismo sino un medio necesario, asociado a cada alternativa $z$ el pasajero $h$ tiene un costo generalizado $C G_{h z}$, correspondiente a la suma de todos los costos, tanto monetarios como no monetarios (donde influye el valor del tiempo para el pasajero $h$ ) [Balcombe et al., 2004; Evans y Morrison, 1997].

Este costo $C G_{h z}$ dependerá de:

1) características del viaje que tiene que realizar el pasajero $h$ : origen-destino, distancia, horario de salida y llegada, etc.;

2) costos monetarios: tarifas, gasto en combustible, peajes;

3) costos no monetarios: esperanza y varianza del tiempo del viaje, acceso a la alternativa de transporte y aspectos vinculados a la calidad del servicio.

Tal como fue resaltado en la sección 1, el concepto de calidad del servicio incluye aspectos como el tiempo de espera, la programación y su cumplimiento, el confort y la seguridad, definiendo esta última como la probabilidad de no sufrir un accidente durante el viaje.

El pasajero $h$ elije la alternativa de transporte $z^{*}$ tal que minimiza su costo generalizado del viaje:

$\forall z \neq z^{*}, C G_{h z^{*}}<C G_{h z}$.

Por lo tanto, en línea con este marco conceptual, el objetivo es estimar cómo un shock sobre la percepción de seguridad del servicio afecta la demanda del mismo. Esto puede entenderse como un efecto información, donde existe información privada sobre el mantenimiento de la infraestructura de los medios de transporte. En este contexto, los pasajeros forman una creencia sobre la probabilidad de ocurrencia de un accidente y la actualizan cada vez que conocen un evento de esta naturaleza.

\subsection{Estrategia de identificación: control sintético}

La estimación del efecto casual de la tragedia de Once sobre la demanda resulta un desafío en términos de identificación. En primer lugar, porque la intervención no puede considerarse como un shock exógeno. En segundo lugar, porque el ramal Once - Moreno presenta diferencias respecto del resto de los ramales, en términos de demanda, infraestructura, material rodante y espacio geográfico.

Por lo tanto, para superar estos problemas de identificación se utiliza la metodología de Control Sintético, desarrollada por Abadie y Gardeazabal (2003). La idea detrás de este enfoque es que cuando la intervención se lleva a cabo a un nivel agregado en vez de a nivel individual (por ejemplo a nivel país, provincial, ramal), una combinación lineal de diferentes unidades proporciona una aproximación más cercana a las características de la unidad expuesta a la intervención que cualquier unidad individual [Castillo et al., 2017].

A lo explicado anteriormente se lo conoce como el método de control sintético y específicamente se considerará una combinación de diferentes ramales para construir un control sintético que 
simule en características relevantes la línea Sarmiento ramal Once - Moreno, antes de que sucediera la tragedia de Once ${ }^{4}$.

Siguiendo el trabajo de Abadie et al. (2010), Abadie et al. (2015) y Castillo et al. (2017) y tomando el caso de la Tragedia de Once, suponemos que existe una muestra de $r=J+1$ ramales, donde $r=1$ corresponde al ramal tratado (Once - Moreno) y donde existen $J$ potenciales controles.

Con respecto al tiempo, $(t=1, \ldots, T)$ donde el ramal 1 (Once - Moreno) es expuesto al tratamiento en el periodo $T_{0}$, y por lo tanto tenemos $1, \ldots, T_{0}$ periodos pre-tratamiento, y $T_{0}+1, \ldots, T$ periodos post-tratamiento.

Siendo $Y_{r t}^{N}$ el outcome o variable de resultado que hubiera sido observado en ausencia de la intervención (Tragedia de Once) para para el ramal $r$ en el periodo $t$, mientras que $Y_{r t}^{I}$ corresponde al outcome que se hubiera observado para el ramal $r$ en el periodo $t$, en caso que $r$ sí fuera expuesto a la intervención en los periodos $T_{0}+1$ hasta $T$. Entonces nos interesa estimar el efecto de la intervención:

$$
\alpha_{r t}=Y_{r t}^{I}-Y_{r t}^{N}
$$

Definimos al Control Sintético como un promedio ponderado de los ramales del grupo de control. $W=\left(w_{2}, \ldots, w_{J+1}\right)$ corresponde al vector $(J \times 1)$ de ponderadores, con:

- $\quad 0 \leq w_{j} \leq 1$ para $j=2, \ldots, J+1$

- $w_{2}+\cdots+w_{J+1}=1$

Elegimos $w^{*}$ tal que:

$$
\begin{array}{r}
\widehat{\alpha_{1 t}}=Y_{1 t}-\sum_{j=2}^{J+1} w_{r}^{*} * Y_{r t} \\
\text { para } t \in\left(T_{0}+1, \ldots, T\right)
\end{array}
$$

Con respecto a los predictores, $X_{1}$ es un vector $(k X 1)$ que contiene los valores de las características pre-intervención de la unidad tratada, y $X_{0}$ vector $(k X J)$ contiene los valores de las mismas variables pero para el grupo de control. Las características pre-intervención en $X_{1} \mathrm{y}$ $X_{0}$ pueden también incluir rezagos de $Y$.

Las diferencias pre-intervención entre las características de la unidad tratada y el control sintético están dadas por $X_{1}-X_{0} W$, y seleccionamos el control sintético $(W)$ tal que minimazamos:

$$
\left\|X_{1}-X_{0} W\right\|_{v}=\sqrt{\left(X_{1}-X_{0} W\right)^{\prime} V\left(X_{1}-X_{0} W\right)}
$$

Donde $V$ corresponde a una matriz diagonal $(k X k)$ con los ponderadores de los predictores, los cuales van a depender de su poder predictivo sobre $Y$.

La selección óptima de $V$ es tal que minimiza la raíz de error cuadrático medio predicho (RMSPE)

$$
\operatorname{RMSPE}=\left(\frac{1}{T_{0}} \sum_{t=1}^{T_{0}}\left(Y_{1 t}-\sum_{j=2}^{J+1} w_{r}^{*} * Y_{r t}\right)^{2}\right)^{\frac{1}{2}}
$$

\footnotetext{
4 Dorna y Ruffo (2017) utilizan también esta metodología para evaluar los efectos de la mejora integral del ferrocarril Roca (ramal Plaza Constitución - La Plata).

5 Se utilizará el paquete synth desarrollado Abadie y Gardeazabal (2003), con la opción de minimización de distancia allopt para obtener resultados completamente robustos, tal como detallan los autores.
} 
Los ponderadores del control sintético están dados por $W^{*}=W^{*}\left(V^{*}\right)$.

Intuitivamente, $\widehat{W}$ es un vector que capta la importancia relativa de cada ramal en el control sintético del ramal 1 (Once-Moreno) y $\widehat{V}$ mide la importancia relativa de cada uno de los $k$ predictores [Firpo y Possebom, 2016].

Como resaltan Castillo et al. (2017), las ventajas de utilizar el método de control sintético pueden resumirse en: 1-transparencia: el método provee una forma sistemática de elegir los ramales de control, haciendo explícita la contribución relativa de cada uno de ellos; 2-las ponderación del grupo de control son positivas y suman uno; 3-flexibilidad: el conjunto de posibles ramales de control pueden restringirse en función de sus características y la respectiva comparabilidad con el ramal tratado; 4-supuesto débil de identificación: permite que varíen en el tiempo los factores inobservables. Por otro lado, sobre esta metodología Athey e Imbens (2017) sostienen: "The synthetic control approach developed by Abadie, Diamond, and Hainmueller $(2010$, 2014) and Abadie and Gardeazabal (2003) is arguably the most important innovation in the policy evaluation literature in the last 15 years"6.

Con respecto a las variables que utilizaremos en este trabajo, definiremos el "Modelo 1" que será utilizado en la sección 4 y tendrá como outcome ${ }^{7}$ un índice que refleja la evolución de la cantidad de pasajeros por tren corrido, tomando como base tres años antes del accidente ${ }^{8}$, el cual será considerado como proxy de demanda. Además, en cuanto a los predictores se utilizará el logaritmo de los kilómetros recorridos, la velocidad promedio, la tasa de puntualidad, la tasa de trenes corridos (con respecto a los trenes programados), la cantidad de estaciones y si el tren es eléctrico (las cuales son fijas en el tiempo), y rezagos del outcome (1 y 12 meses antes del accidente). En cuanto al periodo analizado, se tomarán las características pre-accidente a partir de una ventana de tres años, y se analizarán los resultados en los dos años posteriores al accidente, aunque también se hará el ejercicio de extender los resultados hasta agosto de 2015. Por último, debido a que el accidente también podría generar un efecto negativo sobre el resto de ramales que eran operados por TBA (tanto de la línea Mitre como Sarmiento), consideraremos dos grupos de control para las estimaciones: CS1, que no quita ningún ramal como potencial unidad de control; y CS2, que quita los correspondientes ramales de la línea Sarmiento y Mitre, quedando en total 13 ramales como potenciales unidades controles.

\subsubsection{Robustez}

Una limitación de este método es la inferencia estadística. Para ello, siguiendo Abadie et al. (2015), para resaltar la robustez de las estimaciones se recurre a realizar diferentes test placebo, los cuales pueden ser resumidos de la siguiente forma:

1) Test placebo "in-time": se aplican hipotéticos accidentes al ramal Once - Moreno (la unidad de análisis), pero en distintos momentos de tiempo diferentes al verdadero, y se procede a generar nuevamente el control sintético. El efecto estimado del accidente se podría considerar causal en caso de que el control sintético "falso" no muestre diferencias importantes respecto del ramal Once - Moreno desde el periodo del hipotético accidente hasta el verdadero.

\footnotetext{
${ }^{6}$ Athey, S., \& Imbens, G. W. (2017). "The state of applied econometrics: Causality and policy evaluation". Journal of Economic Perspectives, 31(2), 3-32. Pág.9.

${ }^{7}$ Como se analizará en la sección 3, debido a que antes del accidente el ramal Once - Moreno era el que transportaba la mayor cantidad de pasajeros (y más trenes corría), para utilizar la estrategia de control sintético resulta matemáticamente imposible utilizar como outcome la cantidad de boletos vendidos, como tampoco trenes corridos, ya que al ser valores extremos no es posible generar una combinación lineal a través del resto de los ramales (donde los ponderadores son mayores a 0 y suman 1) [Fremeth et al, 2016].

8 La utilización de otro periodo base, como ser el mes del accidente (febrero de 2012) no altera los resultados obtenidos en este trabajo.
} 
2) Test placebo "across-unit": se aplican hipotéticos accidentes al resto de los ramales y se procede a generar nuevamente el control sintético, para cada uno de ellos. El efecto estimado del accidente podría considerarse causal en caso de que las brechas entre los valores observados y los controles sintéticos sean menores que la del ramal Once - Moreno. Además, como resaltan en Abadie et al. (2015), podría construirse un p-value estimando los efectos placebo para cada ramal de la muestra y luego calculando la fracción ramales con un efecto mayor o igual que el estimado para el ramal Once-Moreno.

3) Test placebo "leave-one-out": se quitan uno por uno los ramales de control (con ponderador positivo) y se procede a generar nuevamente el control sintético. El efecto estimado del accidente podría considerarse causal en caso de que los efectos encontrados no se reduzcan sustancialmente al quitar determinado ramal de control.

\subsection{Extensión de resultados}

Con el objetivo de analizar la persistencia en los resultados obtenidos, se procederá a realizar diferentes ejercicios para estimar el efecto de la tragedia de Once sobre el ramal Once-Moreno.

El primero corresponde a utilizar la estrategia de control sintético, pero utilizando como grupo de control las diferentes líneas de subtes de la Ciudad de Buenos Aires ${ }^{9}$. Si bien corresponden a medios de transporte distintos, se puede simular el contrafactual para el ramal afectado a partir de la evolución de la demanda de los servicios de subtes.

A su vez, se puede extender los resultados utilizando diferentes modelos adicionales al explicado en la sección 3.2. Para ello, utilizando también la estrategia de control sintético se estimará el efecto de la tragedia de Once para los siguientes modelos:

1) Modelo $1^{10}$

Predictores: el logaritmo de los $\mathrm{km}$ recorridos, la velocidad promedio, la tasa de puntualidad, la tasa de trenes corridos (con respecto a los trenes programados), la cantidad de estaciones y si el tren es eléctrico (las cuales son fijas en el tiempo), y dos rezagos del outcome (1 y 12 meses antes del accidente).

Ventana: tres años pre-accidente.

2) Modelo 2

Predictores: predictores del Modelo 1, pero se incorpora el logaritmo de la cantidad de asientos, y tres rezagos adicionales del outcome (6, 18 y 24 meses antes del accidente).

Ventana: tres años pre-accidente.

3) Modelo 3

Predictores: predictores del Modelo 1 pero sin ningún rezago del outcome.

Ventana: tres años pre-accidente.

4) Modelo 4

Predictores: únicamente rezagos del outcome $(1,6,12,18$ y 24 meses antes del accidente).

Ventana: tres años pre-accidente.

5) Modelo 5

Predictores: predictores del Modelo 1

Ventana: cuatro años pre-accidente

Con respecto al outcome utilizado en cada modelo, además del índice de boletos vendidos por tren corrido se realizará las estimaciones para el índice de boletos vendidos.

\footnotetext{
${ }^{9}$ Por cuestiones de distancia entre las estaciones de subtes y las del ramal afectado, no se esperaría un efecto sobre la demanda de subtes a partir del accidente, con la excepción de la línea de subte A. Sin embargo, la misma no es seleccionada como control y por ellos no generaría un sesgo en los resultados.
}

${ }^{10}$ Corresponde al modelo detallado en la sección 3.2, cuyos resultados se analizan en 4.1 
Por otro lado, consideraremos los dos grupos de control definidos en la sección 3.2: CS1, que no quita ningún ramal como potencial unidad de control; y CS2, que quita los correspondientes ramales de la línea Sarmiento y Mitre (TBA), debido a la hipótesis de que el accidente haya tenido un efecto negativo sobre la demanda de todos los ramales que eran operados por TBA.

Adicionalmente, si bien por las características del evento no tenemos variabilidad con respecto al accidente entre los distintos ramales, explotando los datos de panel estimaremos un modelo de efectos fijos, donde utilizaremos una dummy que toma el valor de 1 para el ramal Once-Moreno a partir del momento en el que sucede el accidente, asumiendo que la heterogeneidad inobservable es constante en el tiempo.

\section{Datos y estadísticas descriptivas}

La red de transporte de pasajeros del área metropolitana de Buenos Aires está conformada por 7 líneas de ferrocarril, que en conjunto presentan 23 ramales $^{11}$, junto con 1 tren ligero turístico (Tren de la Costa), 6 líneas de subterráneos, 1 tranvía Premetro y 138 líneas de colectivos, donde todo o parte de su recorrido lo realizan dentro del territorio de la Capital Federal [CNRT, 2017]. Según la ENMODO (2010), en la Región Metropolitana de Buenos Aires el $49 \%$ de las etapas de viajes $^{12}$ se realizan en transporte público, y sobre estos el $13 \%$ se efectúa en ferrocarril, siendo el colectivo el medio de transporte público más utilizado (80\%).

La fuente de información para realizar el presente trabajo corresponde a la Comisión Nacional de Regulación del Transporte (CNRT), quienes aportaron información mensual sobre 22 ramales ${ }^{13}$ para el periodo 2008-2015, correspondiente a boletos vendidos, trenes programados, trenes corridos, trenes puntuales, velocidad comercial, kilómetros recorridos, cantidad de asientos, entre otras. Además, también se dispone de la información de heridos y fallecidos, pero únicamente a nivel línea.

Resulta conveniente destacar que la información provista por la CNRT corresponde a datos administrativos que las Operadoras Ferroviarios proveyeron a la CNRT por obligación del Contrato de Concesión en carácter de declaración jurada, y sujeta a Auditorías (como lo indican los Artículos 14.1 y 14.3 del Contrato) [CNRT - Subgerencia Concesiones Metropolitanas, 1994].

Sobre una limitación de los datos, debido a la ausencia de información sobre el número de pasajeros que viajan en cada ramal de ferrocarril, se utilizará como variable proxy la cantidad de boletos vendidos. Sin embargo, la presencia de evasión en el pago del boleto ${ }^{14}$ podría sesgar los resultados de este trabajo si: 1-la evasión no es constante en el tiempo, y además su evolución es muy volátil y diferente entre ramales; 2-la Tragedia de Once tiene efectos significativos sobre la evasión del ramal afectado. Consideramos poco probable que suceda el primer punto, ya que los niveles de evasión no son muy volátiles y dependen principalmente del monitoreo realizado en los accesos de cada servicio y de la introducción de molinetes en las estaciones. Con respecto al segundo punto, tal como se señala en el informe de la CNRT (2017) es posible que a partir del

\footnotetext{
11 Algunas líneas de ferrocarril tienen un único ramal, como son los casos de la línea Belgrano Norte, Urquiza y San Martín, mientras que el resto de las líneas están formadas por más de un ramal. Además, las líneas pueden ser operadas por empresas privadas y/o estatales. En el Anexo 1 se presenta un mapa con las líneas de ferrocarril del área metropolitana de Buenos Aires.

12 Definiendo el viaje como desplazamiento entre un origen y un destino, cada etapa del viaje corresponde al uso de algún modo de transporte durante el trayecto, y por lo tanto podrían existir viajes con más de una etapa en caso de que se utilice más de un modo durante todo el viaje.

${ }^{13}$ Estos 22 ramales corresponden a las 7 líneas de ferrocarril del área metropolitana de Buenos Aires, los cuales son resaltados en la Tabla 1 . Con respecto al ramal faltante de los 23 , el mismo corresponde al servicio Korn - Chascomús de la línea Roca, el cual entró en vigencia en el 2017.
}

${ }^{14}$ Según estimaciones de la CNRT la evasión promedio en los ramales de ferrocarril se mantuvo en $15 \%$ para el periodo 2003-2009 [CNRT, 2017]. 
accidente haya aumentado la evasión a través de una menor cantidad de boleterías habilitadas, menor control por parte del personal y por decisión propia de los pasajeros. Debido a ello, en la sección 4.4 se realizará un análisis de los posibles sesgos que podrían influir en los resultados del trabajo, y particularmente se considerará el caso de la evasión.

Con el objetivo de analizar la demanda y oferta de cada servicio ferroviario, se presenta el promedio mensual de boletos vendidos y trenes corridos para cada ramal en el periodo previo a la tragedia de Once:

Tabla 1. Promedio mensual de boletos vendidos y trenes corridos a nivel. Febrero 2009 - Enero 2012.

\begin{tabular}{|c|c|c|c|c|}
\hline Ramal & Línea & $\begin{array}{l}\text { Operadora en } \\
\text { enero de } 2012\end{array}$ & $\begin{array}{l}\text { Boletos } \\
\text { vendidos }\end{array}$ & $\begin{array}{l}\text { Trenes } \\
\text { corridos }\end{array}$ \\
\hline Once-Moreno & Sarmiento & TBA & 8.008 .592 & 8.001 \\
\hline Merlo - Lobos & Sarmiento & TBA & 63.984 & 887 \\
\hline Moreno - Mercedes & Sarmiento & TBA & 68.863 & 846 \\
\hline Retiro - J.L. Suarez & Mitre & TBA & 1.792 .754 & 4.234 \\
\hline Retiro - Mitre & Mitre & TBA & 299.276 & 3.047 \\
\hline Retiro - Tigre & Mitre & TBA & 2.678 .107 & 5.212 \\
\hline Victoria - Capilla del Señor & Mitre & TBA & 41.341 & 928 \\
\hline Villa Ballester - Zárate & Mitre & TBA & 52.105 & 877 \\
\hline Retiro - Villa Rosa & Belgrano Norte & Ferrovías S.A.C. & 3.251 .556 & 4.803 \\
\hline Buenos Aires - G. Catán & Belgrano Sur & UGOFE S.A. & 789.051 & 2.728 \\
\hline Buenos Aires - M. C. G. Belgrano & Belgrano Sur & UGOFE S.A. & 271.731 & 1.591 \\
\hline Pte. Alsina - Aldo Bonzi & Belgrano Sur & UGOFE S.A. & 1.616 & 262 \\
\hline Constitución - Bosques & Roca & UGOFE S.A. & 290.837 & 2.633 \\
\hline Constitución - Ezeiza & Roca & UGOFE S.A. & 2.591 .308 & 4.857 \\
\hline Constitución - Gutierrez & Roca & UGOFE S.A. & 851.956 & 1.522 \\
\hline Constitución - Korn & Roca & UGOFE S.A. & 3.234 .754 & 4.962 \\
\hline Constitución - La Plata & Roca & UGOFE S.A. & 2.075 .762 & 2.595 \\
\hline Constitución - Temperley - Claypole & Roca & UGOFE S.A. & 649.554 & 551 \\
\hline Ezeiza - Cañuelas & Roca & UGOFE S.A. & 60.227 & 1.362 \\
\hline Temperley - Haedo & Roca & UGOFE S.A. & 6.723 & 947 \\
\hline Retiro - Pilar & San Martin & UGOFE S.A. & 4.082 .482 & 5.154 \\
\hline Lacroze - General Lemos & Urquiza & Metrovías S.A. & 1.763 .304 & 4.787 \\
\hline
\end{tabular}

Nota: TBA corresponde a Trenes de Buenos Aires S.A, y UGOFE SA a Unidad de Gestión Operativa Ferroviaria de Emergencia S.A.

Fuente: elaboración propia en base a datos de la CNRT.

Como puede apreciarse en la Tabla 1, antes del accidente el ramal Once - Moreno sobresale por ser el que transportaba la mayor cantidad de pasajeros pagos y el que más trenes corría. Como ya fue señalado, al ser valores extremos resulta matemáticamente imposible utilizar estas variables como outcomes en la estrategia de control sintético, debido a las restricciones de los 
ponderadores $w$ discutidas en la sección $2.2\left(0 \leq w_{j} \leq 1 \text { y } w_{2}+\cdots+w_{J+1}=1\right)^{15}$. Por ello, para analizar un indicador más comparable entre ramales, generamos el ratio de boletos vendidos por tren corrido, el cual puede ser interpretado como el nivel promedio de ocupación de los trenes ${ }^{16}$. Sin embargo, como se aprecia en el Gráfico A2 para el periodo previo al accidente (ver Anexo 2), nuevamente sucede que para este indicador el ramal Once - Moreno presentaba los valores extremos (junto con el ramal Consititución - Temperley - Claypole). Por lo tanto, para resolver dicha limitación generamos finalmente nuestro proxy de demanda, que será un índice correspondiente a la evolución de boletos vendidos por tren corrido, tomando como base 2 años antes del accidente (febrero de 2009) ${ }^{1718}$. El gráfico 2 presenta la evolución de dicho índice, resaltando en negro el ramal Once - Moreno, y en línea punteada el promedio del resto de los ramales:

Gráfico 2. Evolución del índice mensual de boletos vendidos por tren corrido a nivel ramal. Febrero 2009 - Enero 2012.

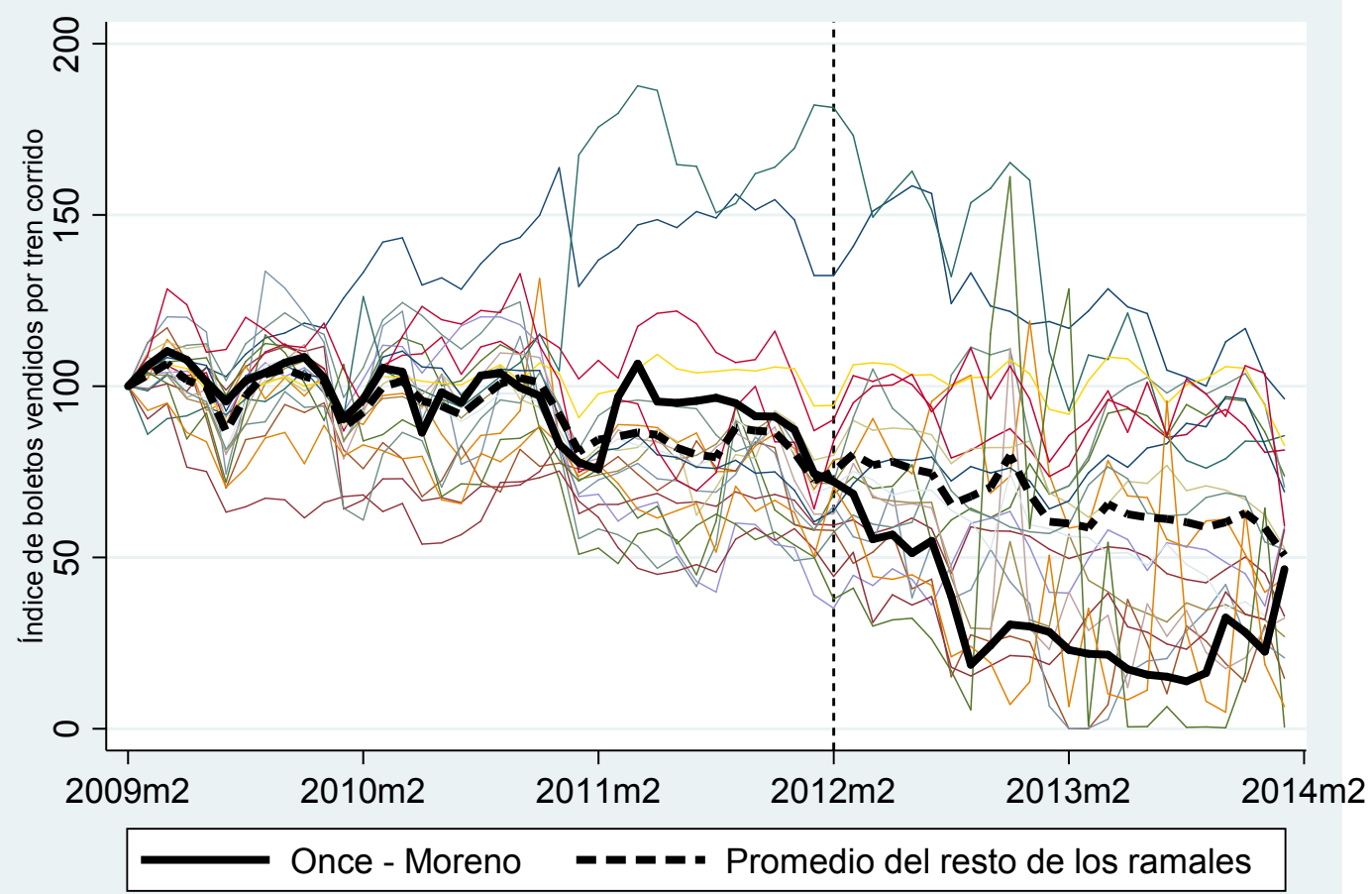

Fuente: elaboración propia en base a datos de la CNRT

Como se aprecia en el gráfico 2, utilizando este índice como proxy demanda, el ramal Once Moreno presenta una evolución similar con respecto al promedio del resto de los ramales, y además se distingue una caída en dicho indicador a partir del accidente en febrero de 2012.

Y con el objetivo de dimensionar la tragedia de Once en términos de heridos y fallecidos, se presentan los siguientes gráficos a nivel línea:

\footnotetext{
15 Tal como se resaltó, al ser valores extremos no es posible generar una combinación lineal a través del resto de los ramales.

${ }^{16}$ Este indicador también disminuye el riesgo de considerar como caídas de demanda reducciones en la venta de boletos causadas por interrupciones del servicio o menor oferta de trenes.

17 Con respecto a la interpretación de dicho índice, debe tenerse en cuenta que está expresado con respecto a febrero de 2009. Por ejemplo, si en febrero de 2010 el índice es 90 (110), ello indica que entre dicho mes y febrero de 2009 la cantidad de boletos vendidos por tren corrido aumentó (cayó) 10\%.
}

${ }^{18}$ En la sección 4.3 también se utilizará como proxy de demanda la evolución de los boletos vendidos. 
Gráfico 3. Evolución mensual de fallecidos por línea de ferrocarril. Periodo 2004-2015.

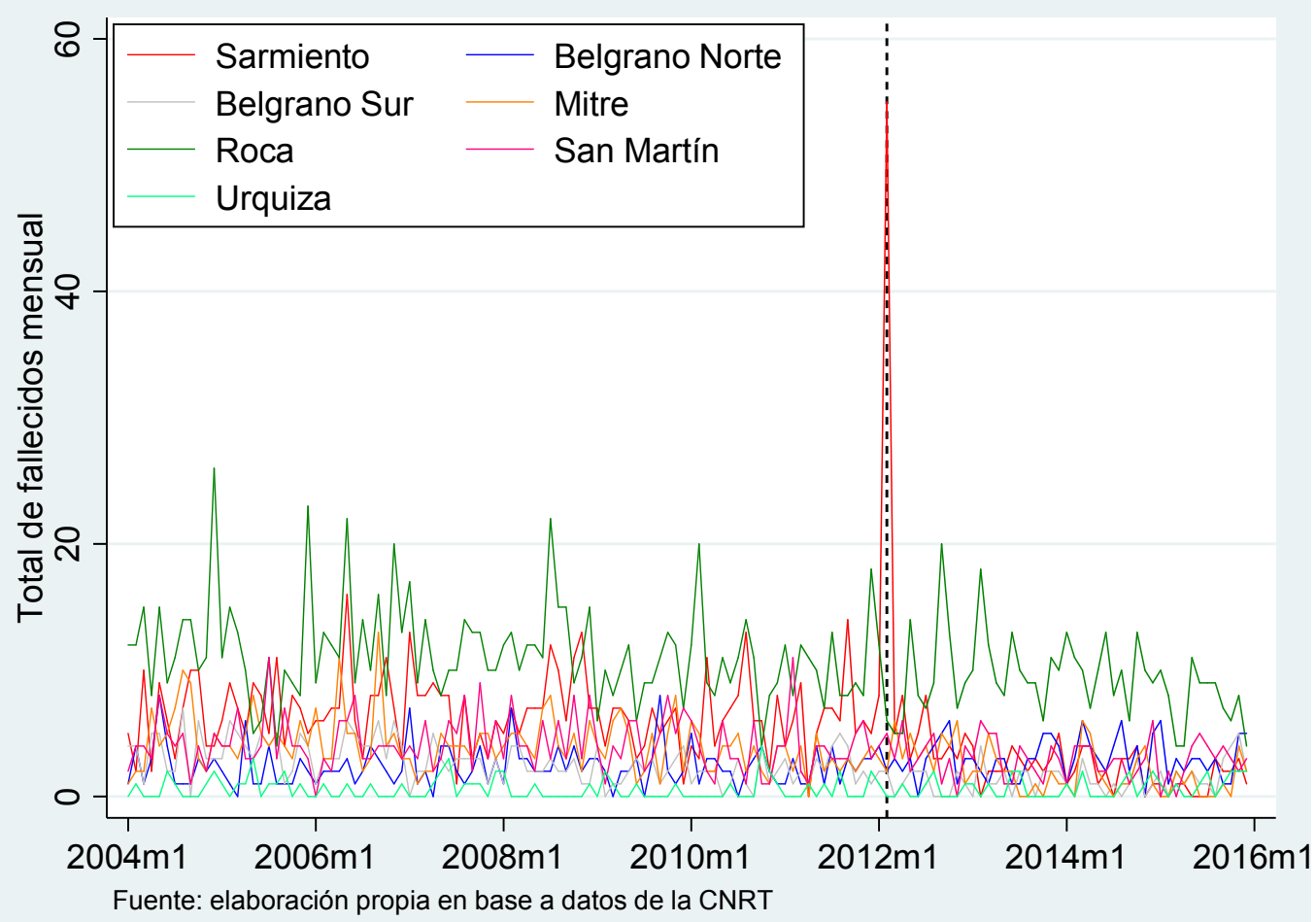

Gráfico 4. Evolución mensual de heridos por línea de ferrocarril. Periodo 2004-2015.

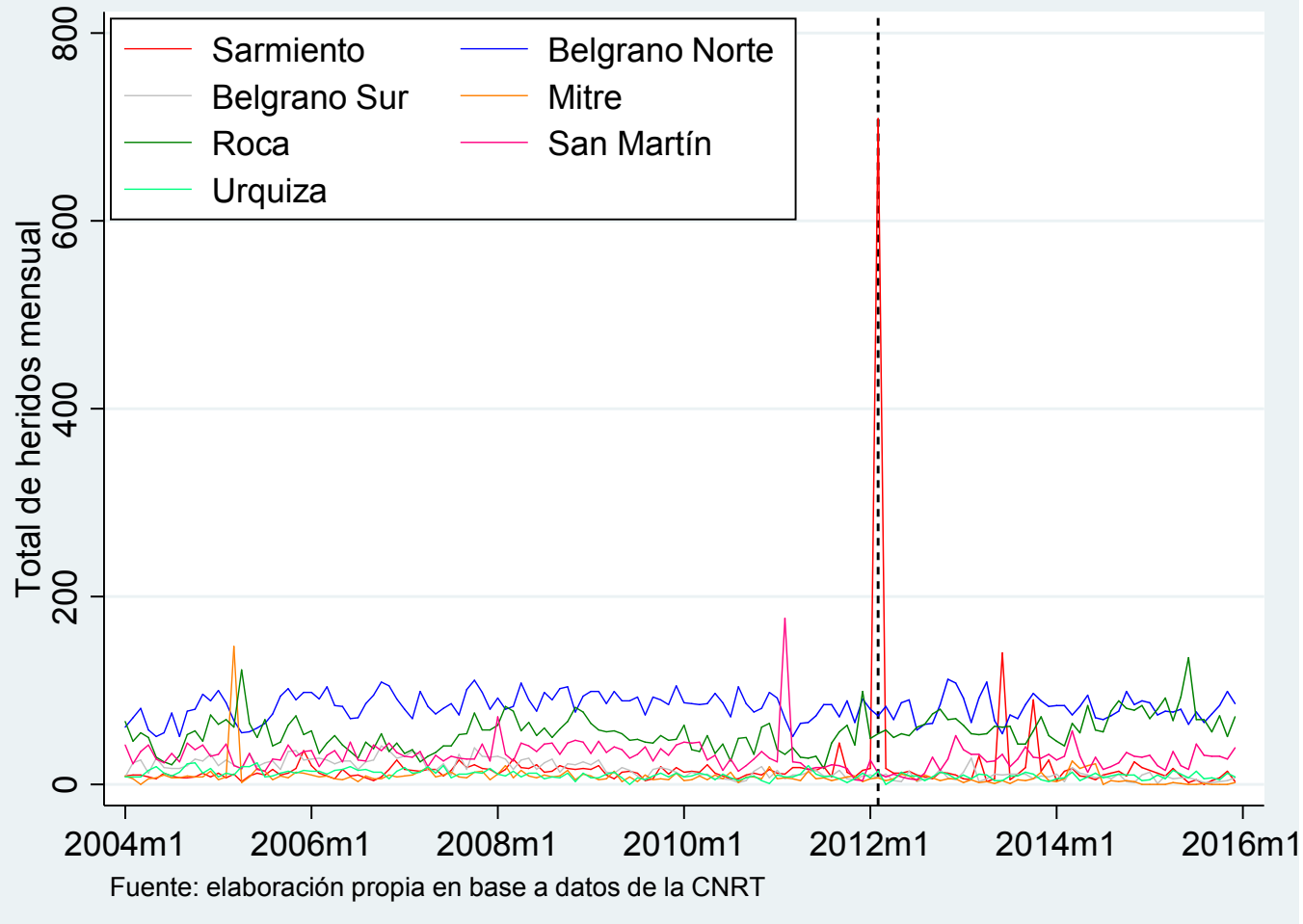

Como puede apreciarse en los gráficos, la Tragedia de Once marca un hito en las tendencias de fallecidos y heridos, evidenciando la gravedad del hecho en términos de seguridad de los pasajeros. 


\section{Resultados \\ 4.1 Resultado principal}

En este apartado se presentan los resultados encontrados al aplicar la metodología de control sintético a nivel ramal mensual, tomando como variable de demanda el índice de boletos vendidos por tren corrido.

Tal como se definió en la sección 3.2, para la generación del control sintético se considerarán todos los ramales para el CS1, y se quitan algunos ramales posiblemente afectados del grupo de control para el CS2 (los otros ramales que también estaban siendo operados por TBA en el momento del accidente).

Consideraremos el Modelo 1, definido con un periodo pre-accidente que abarca desde febrero de 2009 hasta enero 2012, lo que representa 36 meses $^{19}$, y como predictores se utilizarán el logaritmo de los kilómetros recorridos, la velocidad promedio, la tasa de puntualidad, la tasa de trenes corridos (con respecto a los trenes programados), la cantidad de estaciones y si el tren es eléctrico (las cuales son fijas en el tiempo), y rezagos de la variable de demanda (1 y 12 meses antes del accidente).

Como se mencionó en la sección 2.2 , la matriz W capta la importancia relativa de cada ramal en el control sintético, y por ello la Tabla 2 presenta la composición del control sintético del ramal Once - Moreno, construido a partir del proceso de optimización descripto en la sección anterior ${ }^{20}$ :

\footnotetext{
19 La utilización de una ventana de 12, 24 o 48 meses no altera los resultados encontrados en este trabajo.

20 Se utiliza el comando "synth" desarrollado por Abadie y Gardeazabal (2003), con la opción de minimización de distancia "allopt" para obtener resultados completamente robustos, tal como detallan los autores. La utilización de otras opciones de minimización de distancia no modifica los resultados encontrados en este trabajo.
} 
Tabla 2. Ponderadores del control sintético del ramal Once - Moreno

\begin{tabular}{|lrr|}
\hline \multicolumn{1}{|c}{$\begin{array}{l}\text { Ramal } \\
\text { CS1 }\end{array}$} & 0 & $\begin{array}{c}\text { Ponderadores } \\
\text { CS2 }\end{array}$ \\
\hline Buenos Aires - G. Catán & 0 & 0,14 \\
\hline Constitución - Ezeiza & 0 & 0 \\
\hline Constitución - Gutierrez & 0 & 0,084 \\
\hline Constitución - Korn & 0 & 0,084 \\
\hline Constitución - La Plata & 0 & 0 \\
\hline Ezeiza - Cañuelas & 0 & 0 \\
\hline Lacroze - General Lemos & 0 & 0 \\
\hline Merlo - Lobos & 0,115 & - \\
\hline Moreno - Mercedes & 0 & - \\
\hline Pte. Alsina - Aldo Bonzi & 0 & 0 \\
\hline Retiro - J.L. Suarez & 0 & - \\
\hline Retiro - Mitre & 0 & - \\
\hline Retiro - Pilar & 0,536 & 0,63 \\
\hline Retiro - Tigre & 0 & - \\
\hline Retiro - Villa Rosa & 0,349 & 0 \\
\hline Temperley - Haedo & 0 & 0 \\
\hline Victoria - Capilla del Señor & 0 & - \\
\hline Villa Ballester - Zárate & 0 & 062 \\
\hline Constitución - Bosques & 0 & - \\
\hline Constitución - Temperley - Claypole & 0 & 0 \\
\hline
\end{tabular}

Fuente: Elaboración propia en base a datos de la CNRT

Como puede apreciarse en la tabla, para el CS1 los ramales Merlo - Lobos, Retiro - Pilar y Retiro - Villa Rosa son los que minimizan la distancia en la variable de resultado con respecto ramal afectado (Once - Moreno) para los periodos previos a la intervención, siendo Retiro - Pilar el ramal con mayor peso. Mientras que para el CS2 los correspondientes son Buenos Aires - M. C. G. Belgrano, Constitución - Gutierrez, Constitución - Korn, Retiro - Pilar y Constitución Temperley - Claypole, siendo Retiro - Pilar nuevamente el ramal con mayor peso.

A continuación se presenta el promedio ex-ante de los diferentes predictores para el ramal Once - Moreno, sus controles sintéticos y el promedio de ramales ${ }^{21}$. 
Tabla 3. Promedio de variables de control

\begin{tabular}{|lrrrr|}
\hline Variables & $\begin{array}{c}\text { Once } \\
\text { Moreno }\end{array}$ & \multicolumn{1}{l}{ CS1 } & \multicolumn{1}{l}{ CS2 } & Promedio \\
\hline Log. de los km recorridos & 12,5 & 12,2 & 11,9 & 11,1 \\
\hline Velocidad promedio & 35,2 & 37,7 & 38,4 & 36,2 \\
\hline Tasa de trenes corridos & 0,77 & 0,80 & 0,80 & 0,82 \\
\hline Tasa de trenes puntuales & 0,94 & 0,94 & 0,95 & 0,96 \\
\hline Cantidad de estaciones & 16 & 21 & 20 & 15 \\
\hline Trenes eléctricos & 1 & 0 & 0,15 & 0,33 \\
\hline $\begin{array}{l}\text { Índice de boletos por tren corrido } \\
\text { (mes anterior) }\end{array}$ & 74,6 & 78,3 & 81,8 & 72,5 \\
\hline $\begin{array}{l}\text { Índice de boletos por tren corrido } \\
\text { (año anterior) }\end{array}$ & 75,7 & 89,4 & 87,3 & 84,4 \\
\hline
\end{tabular}

Fuente: Elaboración propia en base a datos de la CNRT

Como se mencionó en la sección 2.2, la matriz $\mathrm{V}^{22}$ mide la importancia relativa de cada uno de los predictores. Tal como señala en Abadie et al. (2010), el hecho de que el ponderador de un predictor sea bajo en comparación del resto, implica que dicha variable no tenga un gran poder predictivo sobre la variable de resultado, como es el caso de la variable que indica si el tren es eléctrico y el índice de boletos por tren corrido (para el año anterior al accidente). Esto conlleva a que para los predictores que presentan ponderadores más bajos, exista una mayor discrepancia entre el ramal Once - Moreno y los controles sintéticos, como puede distinguirse en la tabla 3.

A continuación se ilustran los resultados principales del análisis del control sintético, analizando la evolución del índice de boletos vendidos por tren corrido del ramal Once - Moreno en comparación de los dos controles sintéticos, antes y después del accidente:

22 Se presenta la matriz $V$ en el Anexo 3. 
Gráfico 5. Resultado principal

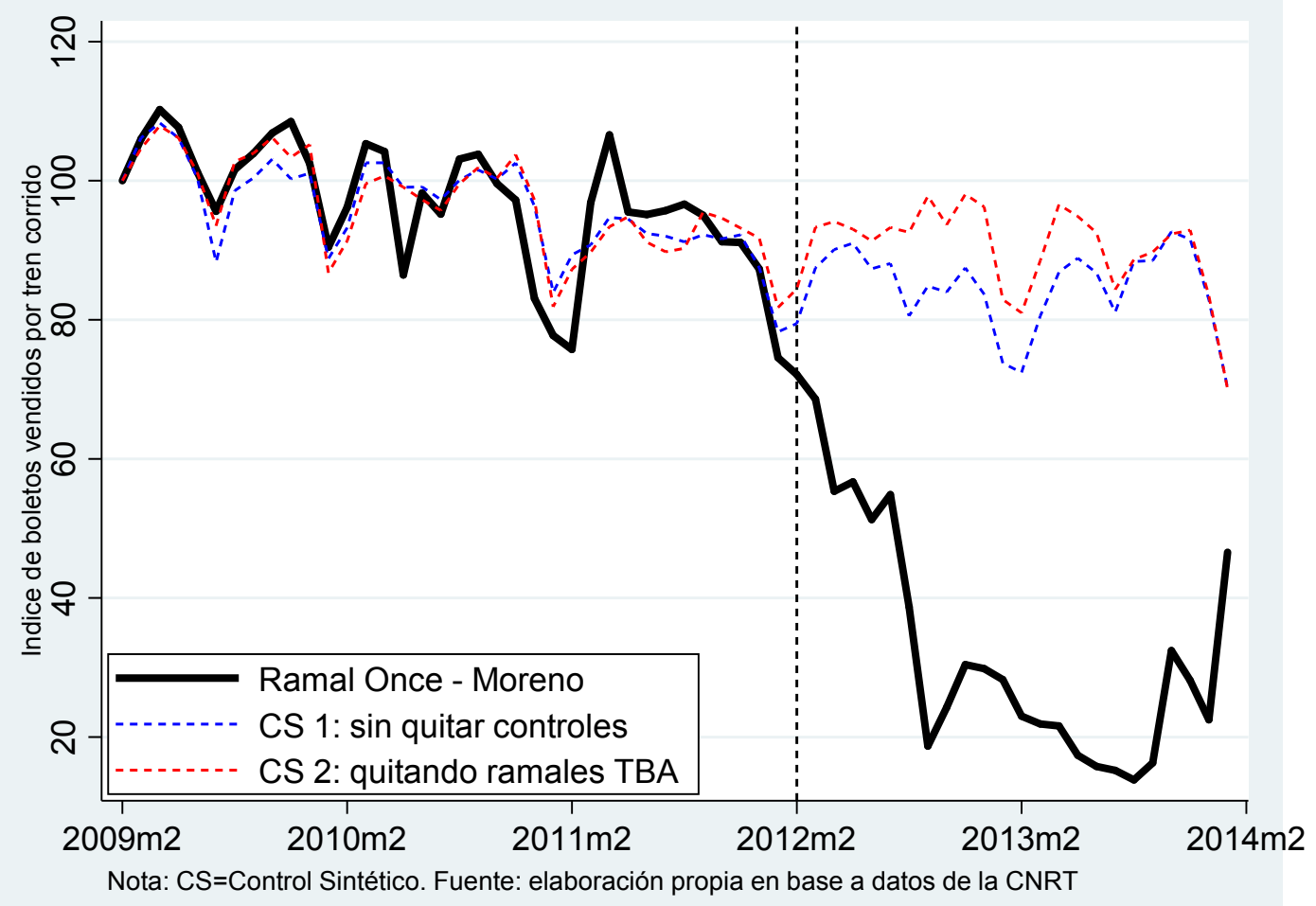

Como puede distinguirse en el gráfico, a partir de la tragedia de Once (22 de febrero de 2012) la evolución de la demanda del servicio de ferrocarril Once - Moreno disminuye en comparación del control sintético, y esto sucede considerando en el grupo de control todos los ramales (CS1), como también quitando los operados por TBA (CS2). Este cambio en la tendencia se puede observar hasta fines de 2013, donde la demanda parece comenzar a reactivarse.

El siguiente gráfico muestra la magnitud del gap o brecha entre el ramal afectado y su control sintético sobre el índice de boletos vendidos por tren corrido, nuevamente para el periodo febrero 2009 - febrero 2014: 
Gráfico 6. Brecha entre el ramal Once - Moreno y su control sintético.

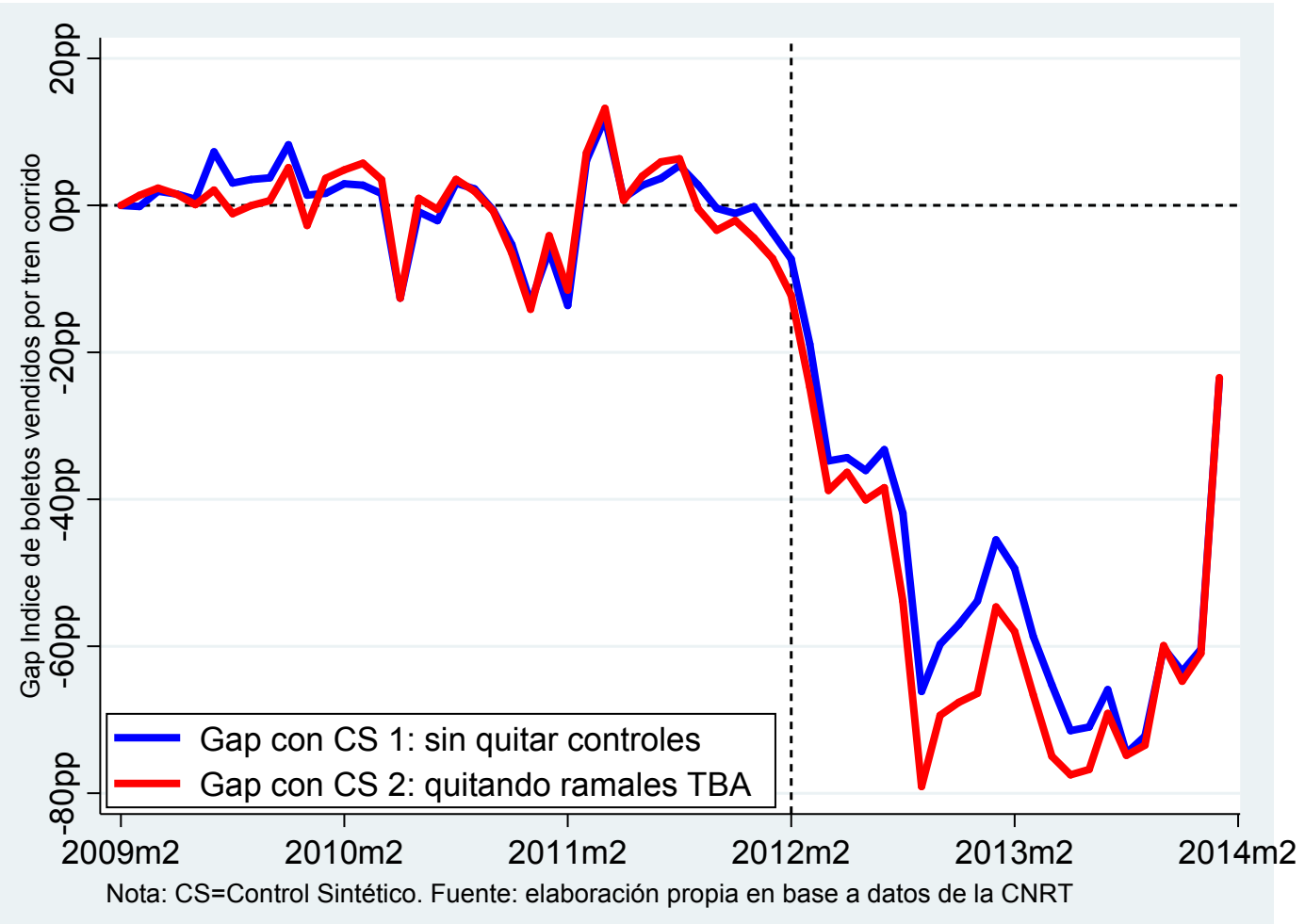

En primer lugar podemos destacar que si bien antes del accidente se distingue una brecha entre el ramal afectado y ambos controles sintéticos, la misma se encuentra dentro del $+/-15 p p$. Sin embargo, como ya se había mencionado, en consecuencia del accidente de Once se produjo una caída en la demanda del servicio afectado. Esta estimación indica que para los dos años posteriores al accidente, la evolución de los boletos vendidos por tren corrido resulta en promedio 53pp menor utilizando CS1 (-62\%), y 59pp utilizando CS2 (-65\%). Es decir, tal como se presumía, al quitar los ramales de TBA dentro de los ramales de control la caída de la demanda es mayor, aportando evidencia de que pudo haber existido un spillover negativo hacia estos ramales producto del accidente.

Con el objetivo de analizar si la brecha se redujo en el largo plazo, a continuación se replican los resultados $^{23}$, pero extendiendo la ventana hasta agosto de 2015 (previo a la electrificación de la línea Roca):

${ }^{23}$ Para este ejercicio se quita el ramal Constitución - Temperley - Claypole, ya que el servicio fue suspendido a partir del 3 febrero de 2014. 
Gráfico 7. Resultado principal: efectos en el largo plazo

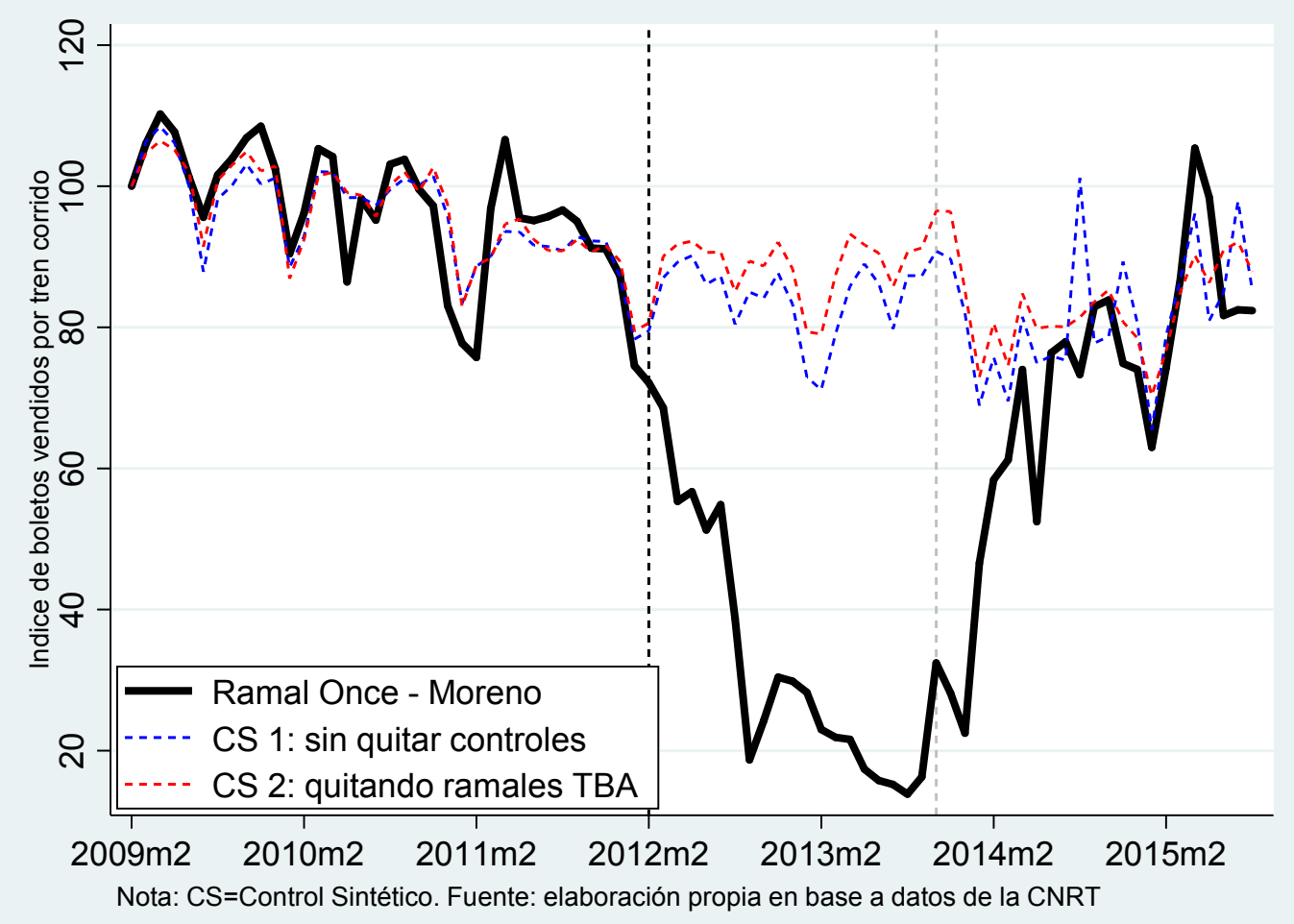

Como se distingue en este último gráfico, la diferencia entre el índice de boletos vendidos por tren corrido del ramal Once - Moreno y los controles sintéticos comienza a reducirse a partir de septiembre del 2013 (19 meses después del accidente), y prácticamente desaparecen desde junio de 2014 (28 meses después del accidente).

Esta mejora en la demanda del servicio podría deberse al cambio de concesión en la operación del servicio de la línea Sarmiento, donde mediante la resolución 1244/2013 del 24 de octubre de 2013 se rescinde el Acuerdo de Operación con UGOMS y queda la operación en manos de SOFSE (Operadora Ferroviaria S.E.). Entre los resultados positivos que se dieron a partir de este cambio de concesión podemos resaltar la entrada en servicio de nuevas formaciones a partir de julio de 2014, renovación de vías y mejoras en el cumplimiento de la programación.

Por lo tanto, en línea con este marco conceptual, esta reactivación en la demanda se correspondería con una nueva actualización en la creencia de los pasajeros sobre la probabilidad de ocurrencia de un accidente, generada por la nueva información sobre estado del servicio del ramal.

\subsection{Robustez}

Test placebo 1: cambio en el tiempo ("In-time" placebo tests)

En este capítulo se aplicará un hipotético accidente al ramal Once - Moreno 36 meses antes de la tragedia de Once, y se procede a generar nuevamente los respectivos controles sintéticos.

La idea detrás de este test es que quizás la caída en la demanda ya sucedía desde antes del accidente por una cuestión exógena, y entonces estaríamos infiriendo de forma errónea que se debe al accidente. Tal como se comentó en la sección 3, el efecto estimado podría considerarse causal en caso de que el "falso" control sintético no muestre diferencias importantes respecto del ramal Once - Moreno desde el periodo del hipotético accidente hasta el verdadero periodo.

Utilizando una ventana de un año, en el Gráfico 7 se simula los controles sintéticos (CS1 y CS2) asumiendo que el accidente hubiera sido en febrero de 2009: 
Gráfico 8. Test placebo in-time: 36 meses antes del accidente

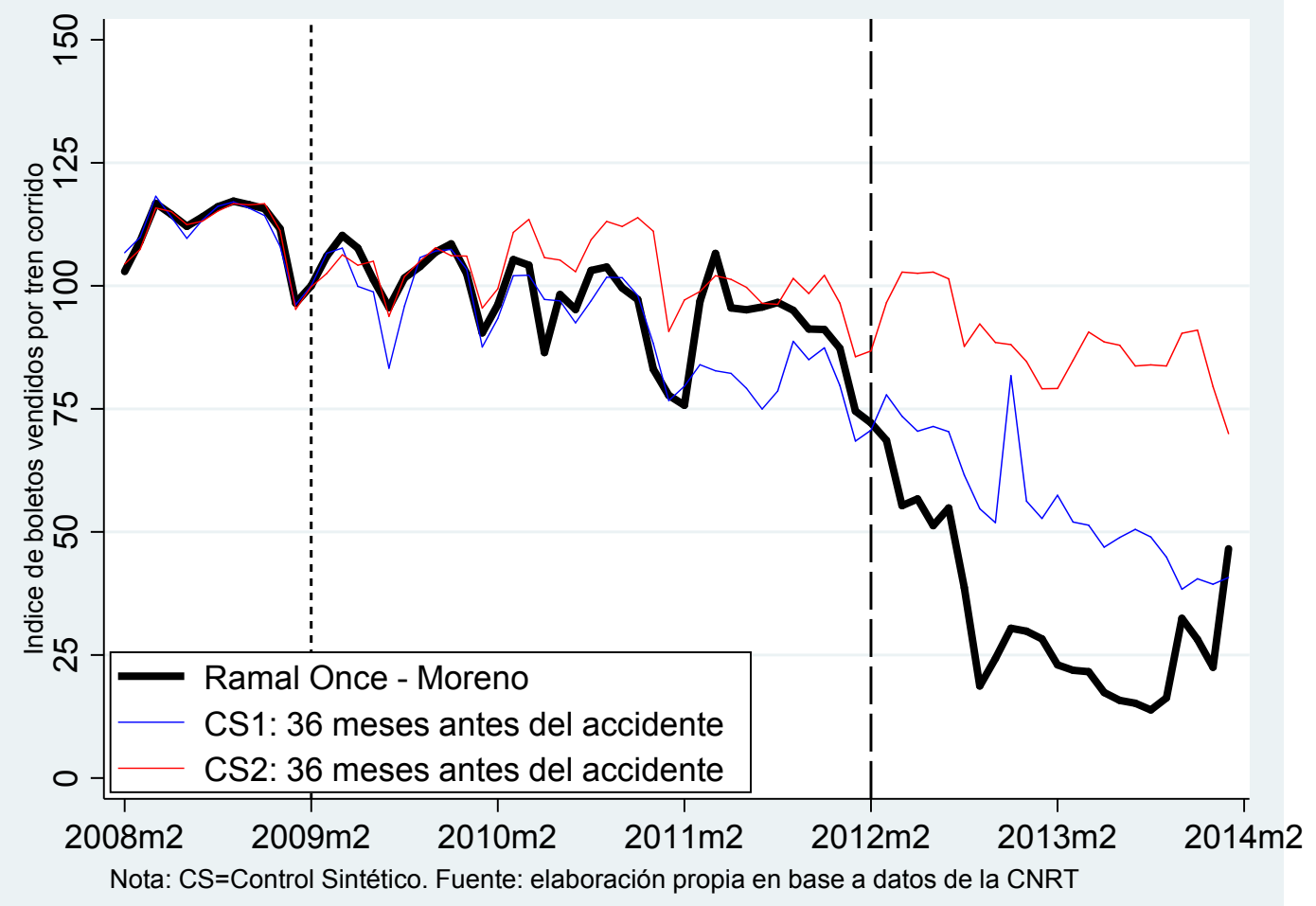

Como puede apreciarse en el gráfico, se simula la trayectoria de la variable de demanda desde febrero de 2009 y es hasta febrero de 2012, que justamente corresponde al verdadero periodo del accidente, donde comienzan a observarse mayores diferencias entre los valores simulados y los observados, tanto para CS1 como para CS2.

Este resultado nos permite realizar dos observaciones: la primera es que se encuentra evidencia de que efectivamente la caída en la demanda se da a partir de febrero de 2012, en línea con el accidente de Once; y la segunda es que parecería adecuado el uso de esta metodología para este tipo de análisis, debido a que los valores simulados por el control sintético resultan muy similares a los observados en ausencia del accidente.

Por lo tanto, esta evidencia apoya la interpretación sobre la causalidad del efecto de la tragedia sobre la demanda debido a dos razones

En el Anexo 4 se presenta el mismo ejercicio, pero tomando hipotéticos accidentes para los 6 , 12, 18 y 36 meses anteriores a la tragedia de Once (separando entre CS1 y CS2) y también se obtiene que la demanda simulada sigue la misma tendencia que la observada hasta el momento del accidente.

\section{Test placebo 2: cambio en la línea tratada ("Across-units" placebo tests)}

En este capítulo se aplicarán hipotéticos accidentes al resto de los ramales y se procederá a generar los respectivos controles sintéticos para cada uno de ellos. Como ya fue resaltado, el efecto estimado del accidente podría considerarse causal en caso de que las brechas entre los valores observados y los controles sintéticos sean menores que la del ramal Once - Moreno.

A continuación se presentan los correspondientes gráficos para CS1 y CS2, resaltando en negro la brecha del ramal Once - Moreno: 
Gráfico 9. Test placebo across-units: CS1

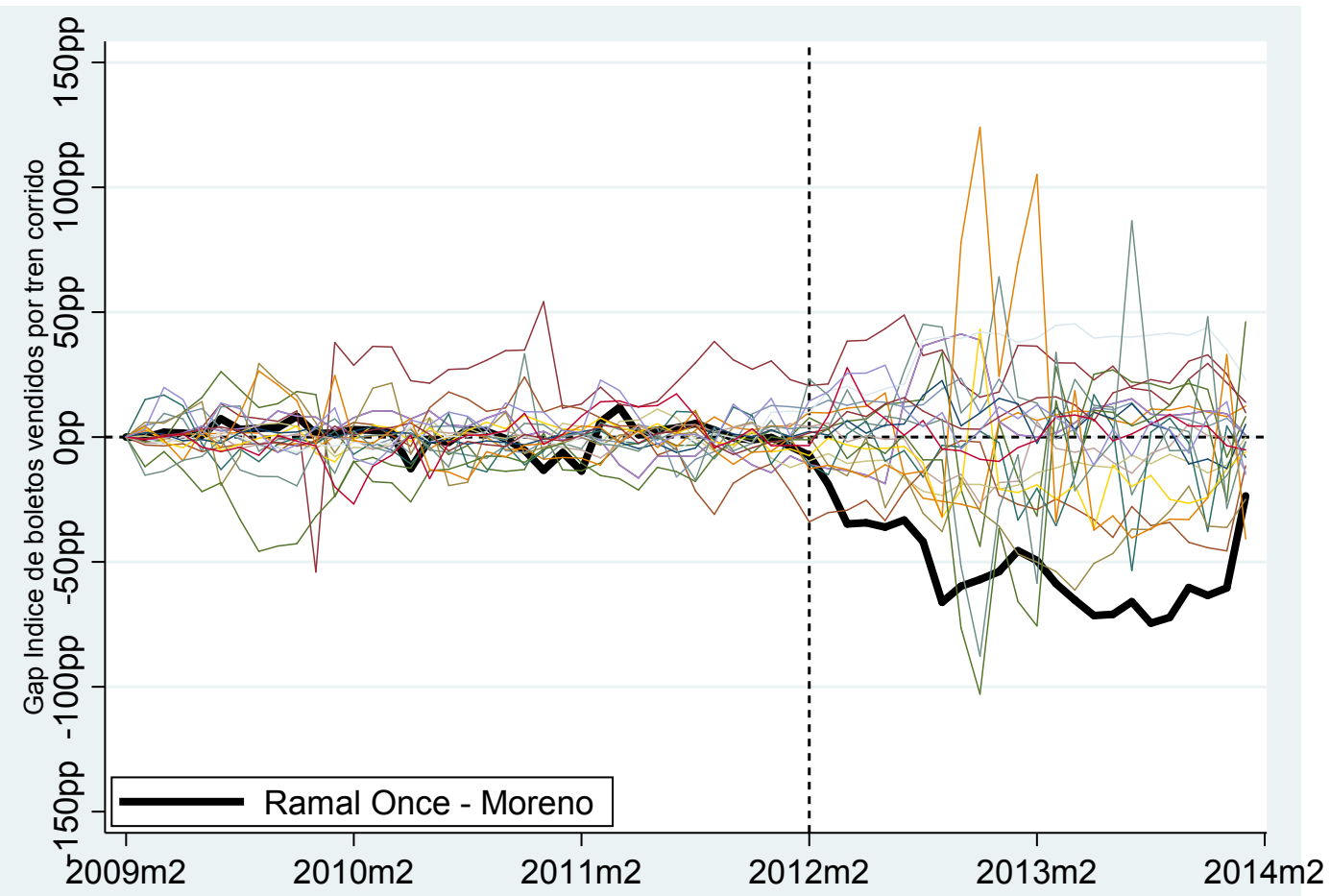

Fuente: elaboración propia en base a datos de la CNRT

Gráfico 10. Test placebo across-units: CS2

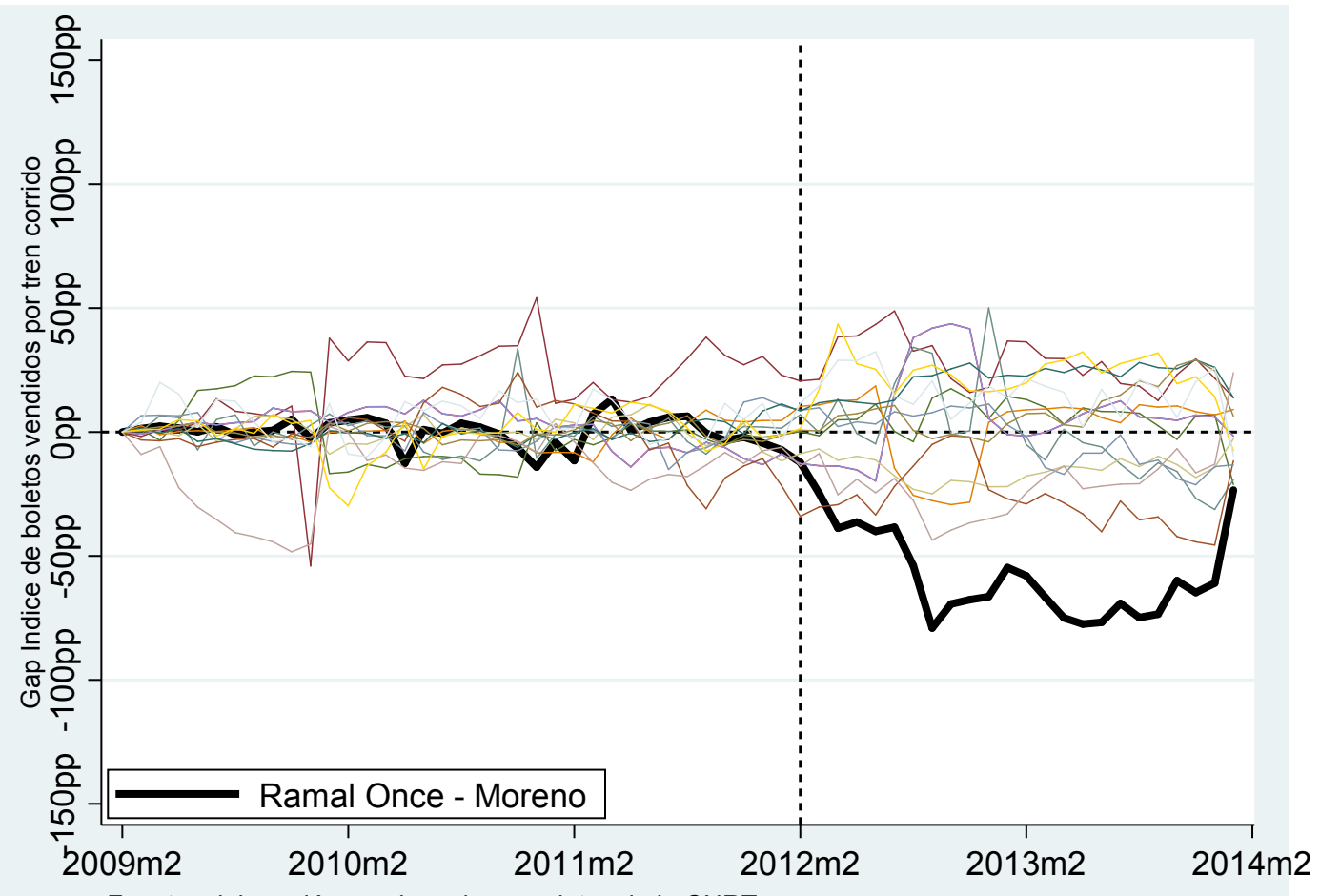

Tal como se distingue en ambos gráficos, el efecto del accidente de Once se vislumbra como uno de los mayores para el ramal Once - Moreno, tanto para CS1 como para CS2. Si bien en el caso de CS1 no resulta tan notorio, al considerar el efecto promedio para los años posteriores 
al accidente el ramal Once - Moreno es el que presenta un mayor efecto negativo a raíz del accidente (53pp), seguido del ramal Moreno - Mercedes (33pp), también operado por TBA.

Además, como resaltan en Abadie et al. (2015), podría construirse un p-value estimando los efectos placebo para cada ramal de la muestra y luego calculando la fracción de ramales que tienen un efecto mayor o igual que el estimado para el ramal Once-Moreno. Como se señaló en la sección 3.2, el RMSPE mide la magnitud de la brecha de demanda entre el ramal Once Moreno y su control sintético. Sin embargo, dada que un elevado RMSPE post-accidente no correspondería a un gran efecto en caso de que el control sintético no simule la demanda preaccidente, para el cálculo del p-value se tomará el ratio entre el RMSPE post y pre-accidente.

Esto conlleva a un p-value de $0,048\left(1 / 21^{24}\right)$ para el efecto de -53pp estimado mediante CS1, y un p-value de 0,071 (1/14) para el efecto de -59pp estimado mediante CS2. Es decir, si se eligiera un ramal al azar de la muestra, la probabilidad de obtener una proporción tan alta como la del ramal Once - Moreno sería entre 5 y $7 \%$.

En el Anexo 5 se presenta la distribución de los ratios del RMSPE, tanto para CS1 como para CS2, donde en ambos casos se destaca el ramal Once - Moreno por su valor extremo.

Por lo tanto, nuevamente los resultados de este test apoyan la interpretación sobre la causalidad del efecto de la tragedia sobre la demanda.

Test placebo 3: cambio en los controles ("Leave-one-out" placebo tests)

En este capítulo se procede a quitar uno por uno los ramales de control (con ponderador positivo) presentados en la sección 4.1 , y se procede a generar nuevamente los respectivos controles sintéticos. Como ya fue mencionado, el efecto estimado del accidente se podría considerar causal en caso de que los efectos encontrados no se reduzcan sustancialmente al quitar determinado ramal de control.

A continuación, en los siguientes gráficos se incorpora la brecha de la demanda entre el ramal Once - Moreno y los nuevos controles sintéticos, tanto para CS1 como para CS2:

${ }^{24}$ El denominador es 21 en lugar de 22 ramales ya que para el caso del ramal Pte. Alsina - Aldo Bonzi no fue posible generar el control sintético. 
Gráfico 11. Test placebo leave-one-out: CS1

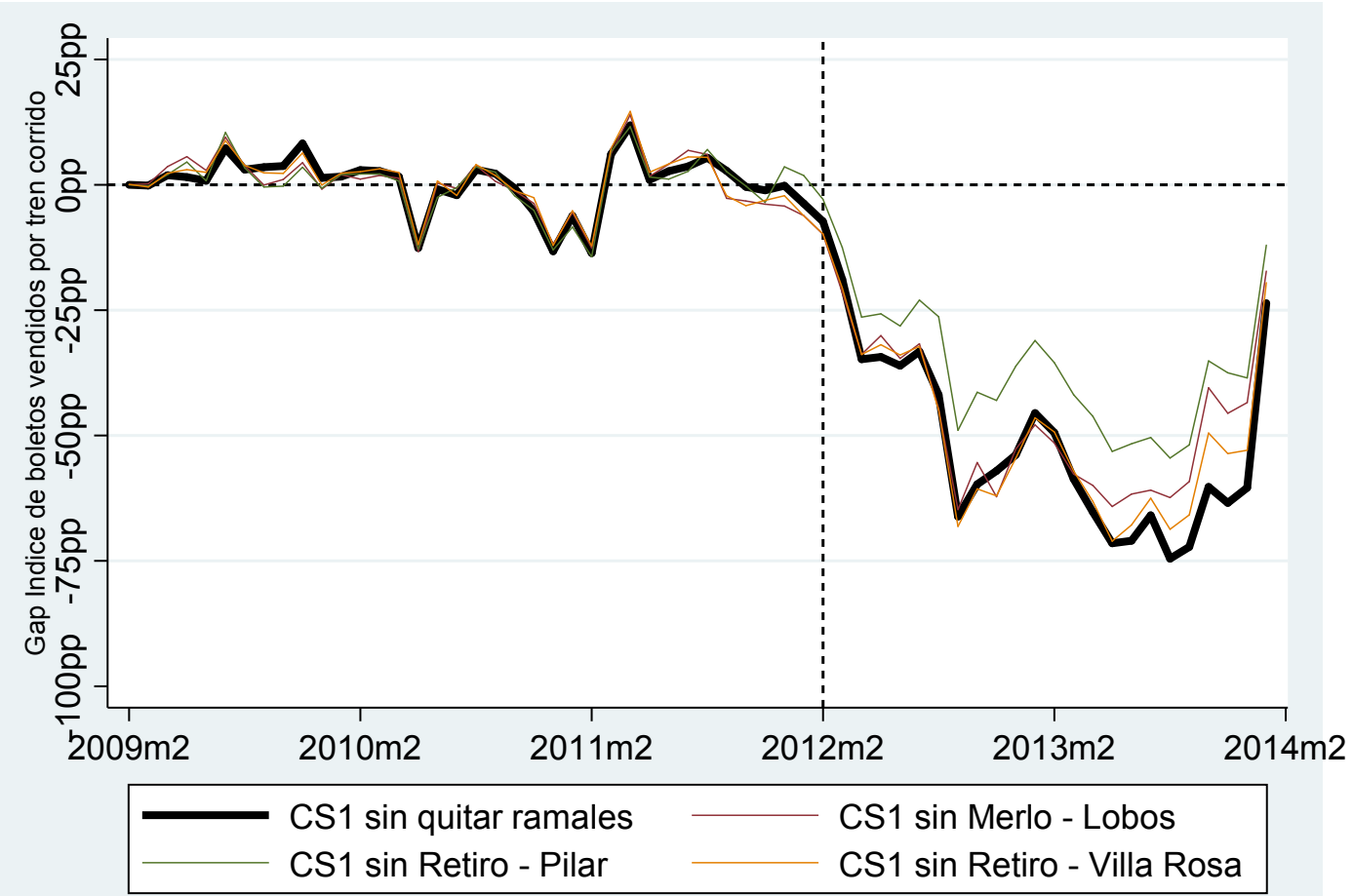

Nota: CS=Control Sintético. Fuente: elaboración propia en base a datos de la CNRT

Gráfico 12. Test placebo leave-one-out: CS2

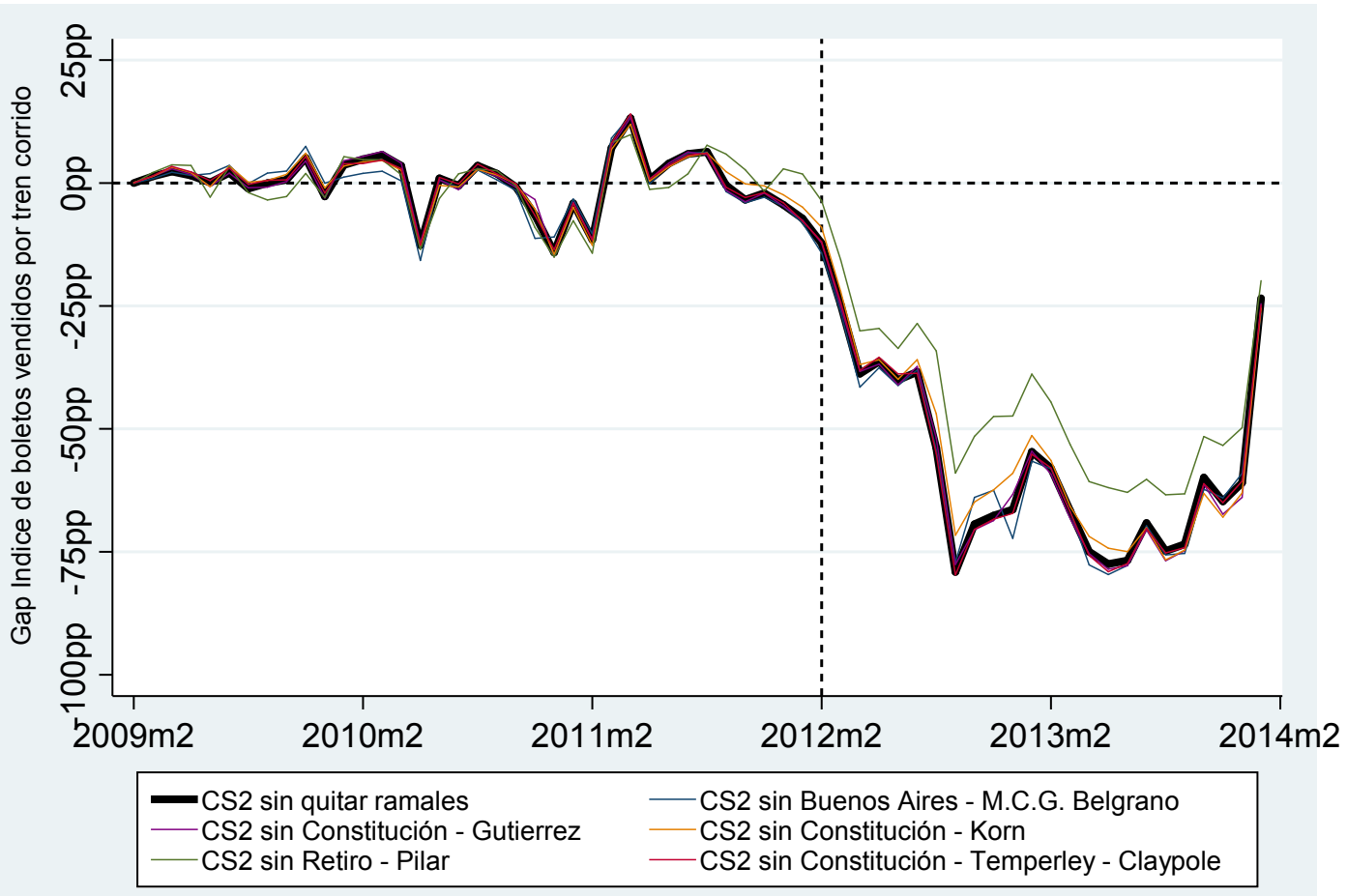

Nota: CS=Control Sintético. Fuente: elaboración propia en base a datos de la CNRT

Como puede apreciarse en los gráficos 11 y 12, si bien en ambos casos el efecto se reduce al quitar al el ramal Retiro - Pilar, el efecto estimado del accidente sobre la demanda del servicio Once - Moreno persiste, aportando nuevamente evidencia sobre la causalidad del efecto de la 
tragedia sobre la demanda. Al quitar dicho ramal como control, el efecto promedio estimado se reduce a $-37 p p$ para CS1 y $-46 p p$ para CS2, siendo originalmente $-53 p p$ y $-59 p p$.

\subsection{Extensión de resultados}

Tal como se comentó en la sección 3.3, si bien corresponden a medios de transporte distintos se utilizará la estrategia de control sintético, pero utilizando como grupo de control las diferentes líneas de subtes de la Ciudad de Buenos Aires. Sin embargo, por cuestiones de ausencia de información la cantidad de subtes corridos, la variable de demanda será el índice de boletos vendidos, y los predictores serán los rezagos de dicha variable para 1 y 12 meses antes del accidente $^{25}$. Los resultados son los siguientes:

Gráfico 13. Control sintético de subtes

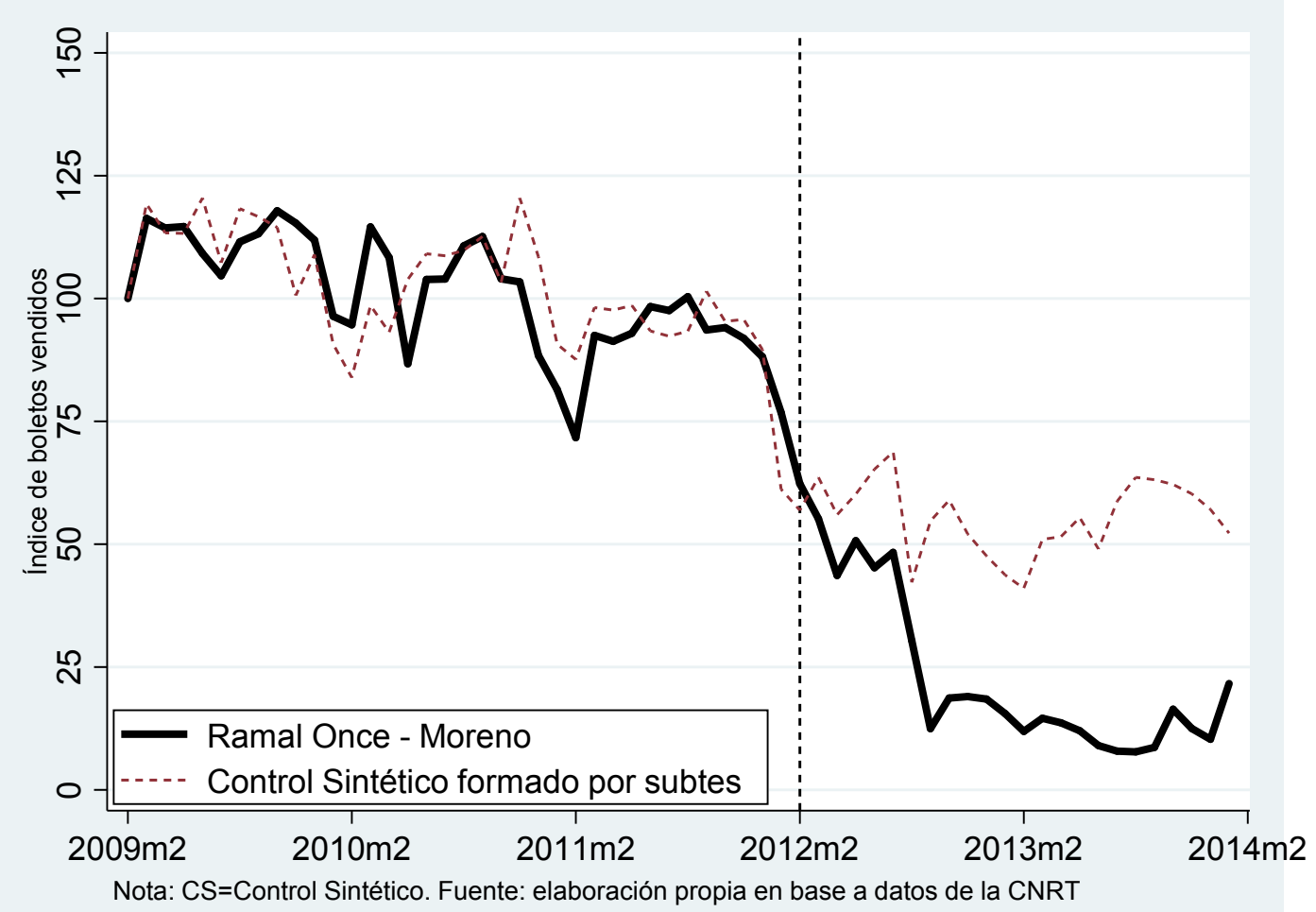

Como puede distinguirse en el gráfico, nuevamente encontramos que a partir de la tragedia de Once la evolución de la demanda del servicio de ferrocarril Once - Moreno disminuye en comparación del control sintético formado por subtes. En este caso encontramos que para los dos años posteriores al accidente, la evolución de los boletos vendidos resulta en promedio 34pp menor que su control sintético. Como ya fue resaltado, por cuestiones de distancia entre las estaciones de subtes y las del ramal afectado, no se esperaría un efecto sobre la demanda de subtes a partir del accidente, con la excepción de la línea de subte A. Sin embargo, esta línea de subte no es seleccionada como control y por ellos no sesgaría lo resultados ${ }^{26}$.

Por otro lado, a continuación presentaremos los resultados para los modelos definidos en la sección 3.3, utilizando la estrategia de control sintético y efectos fijos.

25 Nuevamente se considera el periodo pre-accidente que abarca desde febrero de 2009 hasta enero 2012.

${ }^{26}$ En el Anexo 6 se presenta un análisis sobre esta relación entre el ramal Once - Moreno y la línea de subte $A$. 
Tabla 4. Extensión de resultados

\begin{tabular}{|c|c|c|c|c|c|c|}
\hline & \multicolumn{3}{|c|}{ Índice de boletos vendidos por tren corrido } & \multicolumn{3}{|c|}{ Índice de boletos vendidos } \\
\hline Método & $\mathrm{CS}^{\mathrm{f}}$ & $\mathrm{CS}^{\mathrm{g}}$ & $\mathrm{EF}^{\mathrm{h}}$ & CS1 & CS2 & EF \\
\hline Modelo $1^{\mathrm{a}}$ & $\begin{array}{c}-52,937^{* *} \\
{[0,048]}\end{array}$ & $\begin{array}{c}-58,680^{*} \\
{[0,071]}\end{array}$ & $\begin{array}{c}-35,980^{* * *} \\
(<0,001)\end{array}$ & $\begin{array}{c}-55,430 * * \\
{[0,048]}\end{array}$ & $\begin{array}{c}-57,503^{*} \\
{[0,077]}\end{array}$ & $\begin{array}{c}-30,892^{* * *} \\
(<0,001)\end{array}$ \\
\hline Modelo $2^{b}$ & $\begin{array}{c}-52,065^{\star *} \\
{[0,048]}\end{array}$ & $\begin{array}{c}-57,119^{*} \\
{[0,071]}\end{array}$ & $\begin{array}{c}-36,755^{\star * *} \\
(<0,001)\end{array}$ & $\begin{array}{c}-51,388^{* *} \\
{[0,048]}\end{array}$ & $\begin{array}{c}-58,529^{*} \\
{[0,071]}\end{array}$ & $\begin{array}{c}-31,485^{\star * *} \\
(<0,001)\end{array}$ \\
\hline Modelo $3^{c}$ & $\begin{array}{c}-50,871^{* *} \\
{[0,048]}\end{array}$ & $\begin{array}{c}-59,686^{*} \\
{[0,071]}\end{array}$ & - & $\begin{array}{c}-54,025^{* *} \\
{[0,048]}\end{array}$ & $\begin{array}{c}-58,529 * \\
{[0,077]}\end{array}$ & - \\
\hline Modelo $4^{d}$ & $\begin{array}{r}-28,698 \\
{[0,333]}\end{array}$ & $\begin{array}{c}-55,779^{*} \\
{[0,071]}\end{array}$ & - & $\begin{array}{c}-35,633 \\
{[0,238]}\end{array}$ & $\begin{array}{c}-60,105^{*} \\
{[0,071]}\end{array}$ & - \\
\hline Modelo $5^{\mathrm{e}}$ & $\begin{array}{c}-46,733^{* *} \\
{[0,048]}\end{array}$ & $\begin{array}{c}-59,640 * \\
{[0,077]}\end{array}$ & $\begin{array}{c}-31,750^{* * *} \\
(<0,001)\end{array}$ & $\begin{array}{c}-44,374 \\
{[0,048]}\end{array}$ & $\begin{array}{c}-60,272^{*} \\
{[0,071]}\end{array}$ & $\begin{array}{c}-28,994^{* * *} \\
(<0,001)\end{array}$ \\
\hline
\end{tabular}

a Modelo 1: Los predictores están formados por el log. de los km recorridos, velocidad promedio, tasa de puntualidad, la tasa de trenes corridos, estaciones, si el tren es eléctrico y rezagos de la variable de demanda (1 y 12 meses antes del accidente).

${ }^{b}$ Modelo 2: predictores y ventana del Modelo 1 y además el log. de la cantidad de asientos, y tres rezagos adicionales de la variable de demanda (6, 18 y 24 meses antes del accidente).

${ }^{\mathrm{c}}$ Modelo 3: predictores y ventana del Modelo 1 pero sin ningún rezago de la variable de demanda.

d Modelo 4: únicamente rezagos de la variable de demanda (1, 6, 12, 18 y 24 meses antes del accidente) y ventana del Modelo 1.

e Modelo 5: predictores del Modelo 1 pero con una ventana pre-accidente de 3 años.

f CS1: no se quita ningún ramal del grupo de control

g CS2: se quitan del grupo de control los ramales que eran operados por TBA

h EF: se utiliza como variables independientes los predictores definidos en cada modelo (sin los respectivos rezagos ya que son fijos en el tiempo). El efecto del accidente se define a través de una dummy que toma el valor 1 para el ramal afectado luego del accidente. No se estiman para el modelo 3, ya que al considerar los rezagos es idéntico al 1, ni tampoco el 4 porque solo considera rezagos. Se incluyen efectos fijos mensuales y se especifican errores estándar robustos.

p-values entre paréntesis. p-values computados siguiendo a Abadie et. al (2015) entre corchetes.

${ }^{*}, * * * * *$ indican significatividad al 10,5 y $1 \%$

Tal como se distingue en la tabla, aun cambiando la variable de demanda, la estrategia de estimación, los predictores o la ventana pre-accidente, sistemáticamente encontramos un efecto negativo asociado al accidente de Once, el cual se encuentra entre -29pp y -60pp en función del modelo, la metodología y la variable de demanda analizada. Es menester resaltar que únicamente dos coeficientes de CS1 no son estadísticamente significativos, y corresponden al modelo que incluye exclusivamente rezagos de la variable de demanda.

\subsection{Análisis de sesgos}

En este capítulo intentaremos dar respuesta a diferentes hipótesis sobre sesgos que podrían sufrir las estimaciones de este trabajo, en función de la información disponible.

En primer lugar, como fue señalado en la sección 2 estaríamos sobrestimando el efecto en caso que la caída en nuestra variable de demanda, entendida como índice de boletos vendidos por tren corrido, corresponda a un aumento de la evasión a causa del accidente. Tal como se distingue en el informe de la CNRT (2017), debido a que todos los ramales que eran operados 
por TBA pudieron verse afectados por una mayor evasión a partir del accidente (producto de una menor cantidad de boleterías habilitadas, menor control por parte del personal, y por decisión propia de los pasajeros), una posible hipótesis es que el efecto encontrado podría deberse en su totalidad a este aumento en la evasión del ramal Once - Moreno. En caso que esto fuera cierto, el ramal Once - Moreno no sería el único que sufriría este efecto sobre la evasión, sino todos los que eran operados por TBA (tanto de la línea Sarmiento como la del Mitre) [CNRT, 2017].

Por lo tanto, siguiendo esta hipótesis a continuación se presenta la evolución del índice de boletos vendidos por tren corrido del ramal Once - Moreno, respecto a un nuevo control sintético donde se utilizan como controles únicamente los ramales de la línea Sarmiento y Mitre ${ }^{27}$ :

Gráfico 14. Test de evasión

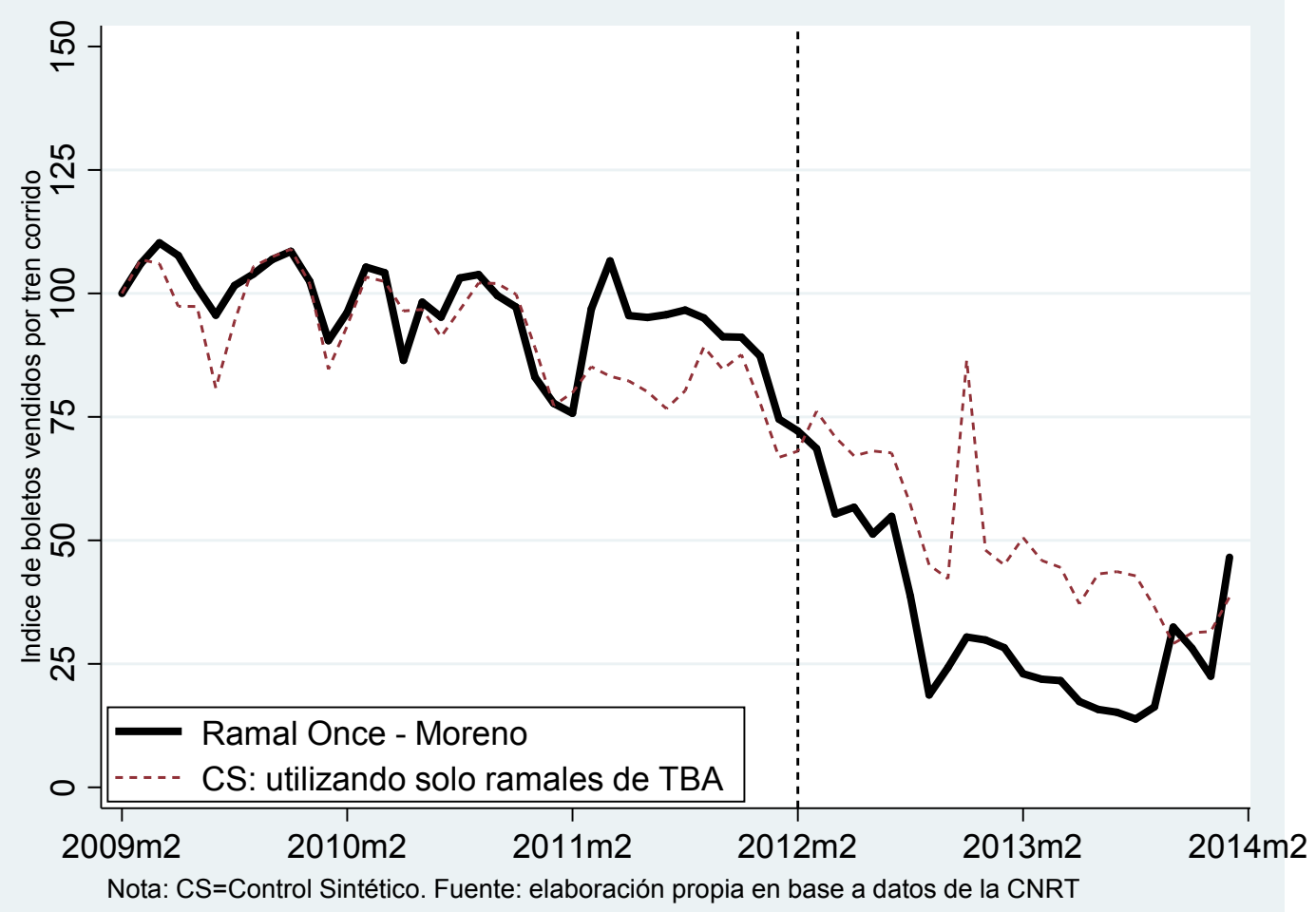

Tal como puedo apreciarse en el gráfico, en este caso el nuevo control sintético también cambia su tendencia a partir de la tragedia de Once, pero la demanda no se reduce tanto como el caso del ramal Once - Moreno. Es decir, siguiendo la hipótesis de que hubo un aumento en la evasión, encontramos una caída promedio de $21 \mathrm{pp}$ en la demanda del servicio vinculada al accidente, para los dos años posteriores del mismo. Si bien la brecha se reduce al comparar con los resultados comentados en la sección 4.1, dado que justamente en este ejercicio los ramales que utilizamos de control eran operados por TBA y también pudieron haber sufrido un efecto negativo por el accidente, este efecto podemos considerarlo como un límite inferior.

Además, también estaríamos sobreestimando el efecto si la caída de la demanda se debiera al incumplimiento de la programación y/o caída de los trenes corridos [Mohring, 1972]. Si bien las estadísticas en el informe de la CNRT (2017) indican que luego del accidente cayó el cumplimiento de la programación y la cantidad de trenes corridos, en primer lugar podemos resaltar que en las estimaciones con efectos fijos (Tabla 4) se utilizó también una variable independiente sobre el cumplimiento de la programación (tasa de trenes corridos) y se encontró

${ }^{27}$ La composición del control sintético queda definida por los siguientes ramales: Retiro - Tigre (61\%), Retiro - Mitre (35\%) y Pte. Alsina - Aldo Bonzi (4\%). 
un efecto asociado al accidente entre -32pp y -37pp para el índice de boletos vendidos por tren corrido, y entre $-29 p p$ y $-31 p p$ para el índice de boletos vendidos ${ }^{28}$. En segundo lugar, al utilizar como controles los ramales que eran operados por TBA, tal como se hizo en el test de evasión, estaríamos comparando el ramal Once - Moreno con ramales que tuvieron una evolución similar en términos de cumplimiento de la programación, y en icho test se encontró una caída promedio de $21 \mathrm{pp}$ en la demanda del servicio vinculada al accidente. $Y$ en tercer lugar, vinculado a la posibilidad de un efecto en la demanda ocasionado por la caída en los trenes corridos, tal como se distingue en la Tabla 4 el efecto negativo vinculado al accidente persiste al utilizar diferentes variables de demanda, tanto con el índice de boletos vendidos como con el índice de boletos vendidos por tren corrido, lo cual sería incompatible con la hipótesis de que el efecto proviene únicamente por la caída de la oferta.

Por último, estaríamos subestimando el efecto de la caída de la demanda si: A-existe un efecto negativo en todos los ramales, además de los operados por TBA; B-existen pasajeros que no se informaron del accidente.

En cuanto al punto $A$, si realizamos el ejercicio de control sintético para todos los ramales pero utilizando los subtes como unidades de control, encontramos que todos los ramales de TBA tuvieron efectos negativos a partir del accidente: algunos en mayor medida, como Once - Moreno (-34pp) y Retiro - Mitre (-14pp), mientras que en el caso del ramal Villa Ballester - Zárate el efecto fue casi nulo $(-0,7 p p)$. Sin embargo, solo uno de los ramales que no era operado por TBA tuvo también un efecto negativo, y es el caso del ramal Buenos Aires - González Catán (-10pp), pero como se distingue en la Tabla 2 no formó parte de la composición del control sintético del ramal Once - Moreno, y por lo tanto no subestimaría los efectos analizados en este trabajo. Además, vinculado a este punto tendríamos un sesgo en las estimaciones si hubiéramos utilizados como unidades de control ramales complementarios (o substitutos) a Once - Moreno, ya que el accidente podría afectarlos de forma negativa (o positiva) en términos de demanda. Tal como se distingue en el mapa del Anexo 1, si bien no se aprecian substitutos directos por una cuestión de cercanía, con respecto a la complementariedad esto podría suceder con los ramales Temperley - Haedo, de la línea Roca, y el ramal Merlos - Lobos, también de la línea Sarmiento (como es el caso de Once - Moreno). Sin embargo, en cuanto al ramal Temperley - Haedo no fue utilizado como control en ninguna de las estimaciones, y si bien el ramal Merlos - Lobos es uno de los controles en CS1, el mismo es quitado en CS2 por ser uno de los ramales de TBA, y por lo tanto corregiría este posible sesgo.

$Y$ en cuanto al punto $B$, la Tragedia de Once tuve gran repercusión mediática, tal como se presenta en Anexo 7.

${ }^{28}$ Además, el efecto persiste si en dicho modelo se controla por la interacción entre el accidente y la tasa de demorados. 


\section{Conclusiones}

Las ciudades de América Latina, a diferencia de las ciudades de países desarrollados, se caracterizan por una escasa e inadecuada infraestructura de movilidad, lo cual impacta sobre la disponibilidad y calidad de los medios de transporte urbano [CAF, 2017].

Entendiendo que la movilidad no es un fin en sí mismo sino un medio necesario para acceder a diferentes oportunidades, las personas toman decisiones sobre como trasladarse en función de las alternativas de transporte disponibles. Dicha decisión va a depender también de las características del viaje que tiene que realizar, los costos monetarios y otros atributos no monetarios, como por ejemplo la calidad del servicio. Vinculado a la calidad del viaje podemos resaltar la disponibilidad, accesibilidad, información, tiempo, servicio al cliente, comodidad, impacto ambiental y seguridad del servicio.

Con respecto a la evidencia de la literatura, son numerosos los trabajos que estudian los determinantes de la demanda de transporte público, pero reducidos los que incorporan atributos vinculados a la seguridad.

El objetivo de este trabajo consiste en estimar cómo un shock sobre la percepción de seguridad de un servicio de transporte afecta la demanda del mismo. Para ello se estudia un accidente ferroviario en la Ciudad de Buenos Aires, conocido como la tragedia de Once.

Para estimar el efecto del accidente sobre la demanda se utilizó la metodología de Control Sintético desarrollada por Abadie y Gardeazabal (2003). Específicamente se consideró como grupo de control una combinación de diferentes ramales para construir un control sintético que simule en características relevantes el ramal afectado, antes de que sucediera el accidente.

Siendo los ramales Merlo - Lobos, Retiro - Pilar y Retiro - Villa Rosa los que conformaron el grupo de control (CS1), los resultados indican que para los dos años posteriores al accidente la evolución de los boletos vendidos por tren corrido resultó en promedio 53pp menor que el control sintético. Además, si se excluyen los ramales (CS2) que también pudieron ser afectados por el accidente, el efecto estimado sobre la demanda resulta de $-59 \mathrm{pp}$. Sin embargo, analizando si el efecto identificado persiste en largo plazo encontramos que declina a partir de 19 meses luego del evento, hasta desaparecer luego de 28 meses, tanto para CS1 como para CS2. Esta reactivación en la demanda del servicio correspondería con una actualización en la creencia de los pasajeros sobre la probabilidad de ocurrencia de un accidente. Esto se generaría por la nueva información sobre estado del ramal, ya que en octubre de 2013 la operación del servicio queda en manos de SOFSE, lo cual se acompañó con la entrada en servicio de nuevas formaciones a partir de julio de 2014, renovación de vías y mejoras en el cumplimiento de la programación.

Con el objetivo de analizar la validez de los resultados encontrados se realizaron diferentes test de robustez.

En primer lugar, se aplicó un hipotético accidente al ramal Once - Moreno 36 meses antes del verdadero accidente, y se generó nuevamente los respectivos controles sintéticos. Luego se simuló la trayectoria de la variable de demanda desde febrero de 2009 y es hasta febrero de 2012, que justamente corresponde al verdadero periodo del accidente, donde comienzan a observarse diferencias significativas entre los valores simulados y los observados, tanto para CS1 como para CS2.

En segundo lugar, se aplicaron hipotéticos accidentes al resto de los ramales y se generaron los respectivos controles sintéticos para cada uno de ellos, encontrándose que el efecto del accidente se vislumbra como uno de los mayores para el ramal Once - Moreno, tanto para CS1 como para CS2. Además, siguiendo a Abadie et al. (2015) se estimaron p-values a partir del ratio entre el RMSPE post y pre-accidente, siendo de 0,048 para CS1 y 0,071 para CS2.

En tercer lugar, se quitaron uno por uno los ramales de control para CS1 y CS2, y se generaron nuevamente los respectivos controles sintéticos. Si bien en ambos casos el efecto se reduce al quitar el ramal Retiro - Pilar, el efecto estimado se reduce a -37pp para CS1 y -46pp para CS2. 
Luego, con el objetivo de analizar la persistencia en los resultados obtenidos se realizó diferentes ejercicios para estimar el efecto de la tragedia de Once sobre el ramal Once-Moreno.

Utilizando también la estrategia de control sintético se consideró como grupo de control las diferentes líneas de subtes de la Ciudad de Buenos Aires, encontrando que para los dos años posteriores al accidente la evolución de los boletos vendidos resulta en promedio 34pp menor que su control sintético.

Por otro lado, también se extendieron los resultados cambiando la variable de demanda, la estrategia de estimación, los predictores y la ventana pre-accidente, y encontramos que persiste el efecto negativo asociado al accidente de Once, el cual se encuentra entre -29pp y -60pp en función del modelo, la metodología y la variable de demanda analizada, para los dos años posteriores al accidente.

Por último, se realizaron diferentes ejercicios para identificar posibles sesgos en las estimaciones de este trabajo.

En primer lugar, para analizar si el efecto negativo sobre la demanda está causado por un aumento en la evasión, se generó un control sintético utilizando únicamente los ramales TBA, ya que la hipótesis es que todos ellos sufrieron este aumento. Se encontró que el efecto estimado se reduce a $-21 \mathrm{pp}$, y dado que los controles también pudieron haber sufrido un efecto negativo por el accidente este efecto podemos considerarlo como un límite inferior.

En segundo lugar, podríamos sobreestimar el efecto si la caída de la demanda se debiera al incumplimiento de la programación y/o caída de los trenes corridos. Sin embargo, consideramos que esta hipótesis no es válida ya que el efecto negativo persiste al controlar por tasa de trenes corridos, y al utilizar como variable de demanda tanto el índice de boletos vendidos como el índice de boletos vendidos por tren corrido. Por otro lado, al utilizar como controles los ramales que eran operados por TBA, tal como se hizo en el test de evasión, estaríamos comparando el ramal Once - Moreno con ramales que tuvieron una evolución similar en términos de cumplimiento de la programación.

Además, estaríamos subestimando el efecto si todos los ramales sufrieron un efecto negativo sobre la demanda, o si existen pasajeros que no se informaron del accidente. Con respecto a la hipótesis de spillovers negativos a todos los ramales, se utilizó los subtes como unidades de control y se encontró que con la excepción del ramal Buenos Aires - González Catán, el cual no fue utilizado como ramal de control en las estimaciones de este trabajo, únicamente los ramales operados por TBA sufrieron efectos negativos a partir del accidente. A su vez, también se consideró el problema de utilizar como unidades de control ramales substitutos y/o complementarios a Once - Moreno, ya que el accidente también podría haber tenido un impacto sobre ellos en términos de demanda. $Y$ en cuanto al conocimiento del accidente por parte de los pasajeros, se resaltó que el mismo tuvo una gran repercusión mediática. 


\section{Referencias bibliográficas}

- Abadie, A., \& Gardeazabal, J. (2003). "The economic costs of conflict: A case study of the Basque Country". American economic review, 113-132.

- Abadie, A., Diamond, A., \& Hainmueller, J. (2010). "Synthetic control methods for comparative case studies: Estimating the effect of California's tobacco control program". Journal of the American statistical Association, 105(490), 493-505.

- Abadie, A., Diamond, A., \& Hainmueller, J. (2015). "Comparative politics and the synthetic control method". American Journal of Political Science, 59(2), 495-510.

- Athey, S., \& Imbens, G. W. (2017). "The state of applied econometrics: Causality and policy evaluation". Journal of Economic Perspectives, 31(2), 3-32.

- Balcombe, R., Mackett, R., Paulley, N., Preston, J., Shires, J., Titheridge, H., Wardman, M. \& White, P. (2004). "The demand for public transport: a practical guide". Transport Research Laboratory Report TRL593.

- Barbero, J. (2012). "Ferrocarriles metropolitanos: de la tragedia de Once a una política integral de transporte de calidad para la equidad". Documento de Políticas Públicas/Recomendación N¹05. Buenos Aires: CIPPEC.

- CAF - Banco de Desarrollo de América Latina (2016). "Encuesta sobre acceso, calidad y satisfacción con los servicios públicos en América Latina". Disponible en línea: https://www.caf.com/es/temas/i/investigacion-para-el-desarrollo/encuesta-caf/

- CAF - Banco de Desarrollo de América Latina (2017). "Crecimiento urbano y acceso a oportunidades: un desafío para América Latina". Reporte de Economía y Desarrollo. Bogotá: CAF.

- Cameron, M. H., Haworth, N., Oxley, J., Newstead, S., \& Le, T. (1993). "Evaluation of Transport Accident Commission road safety television advertising" (No. 52).

- Castillo, V., Garone, L. F., Maffioli, A., \& Salazar, L. (2017). "The causal effects of regional industrial policies on employment: A synthetic control approach". Regional Science and Urban Economics, 67, 25-41.

- Comisión Nacional de Regulación del Transporte (CNRT) (2017). "Informe Estadístico Anual 2017 - Red Ferroviaria de Pasajeros del Área Metropolitana de Buenos Aires". Gerencia de Control de Gestión Ferroviaria Comisión Nacional de Regulación del Transporte.

- Comisión Nacional de Regulación del Transporte (CNRT). (2001). "Anexo XXVII del Contrato de Concesión de T.B.A. S.A. Grupo de Servicios 1 y 2 (Líneas Mitre y Sarmiento)". Subgerencia de Concesiones Metropolitanas.

- Comisión Nacional de Regulación del Transporte (CNRT). (2001). "Contrato de concesión con las adiciones incorporadas por la ADDENDA. T.B.A. S.A. Grupo de Servicios 1 y 2 (Líneas Mitre y Sarmiento)". Subgerencia de Concesiones Metropolitanas .Disponible en línea: http://168.101.24.238/informeffcc2010/Index/Normas/Contrato\%20TBA\%20con\%20ADDENDAS \%20total.pdf

- Comisión Nacional de Regulación del Transporte (CNRT). "Estadísticas de transporte ferroviario". Disponible en línea: https://www.argentina.gob.ar/cnrt/estadisticas-ferroviarias

- Dell'Olio, L., Ibeas, A., de Oña, J., \& de Oña, R. (2017). "Public Transportation Quality of Service: Factors, Models, and Applications". Elsevier.

- Despouy, L. (2014a). "Transporte ferroviario: Informe sectorial del Presidente de la Auditoría General de la Nación. Una década al cuidado de los fondos públicos”. Auditoría General de la Nación.

- Despouy, L. (2014b). "Accidentes ferroviarios y las tragedias de Once, Flores y Zanjitas: Informe Especial del Presidente de la Auditoría General de la Nación. Una década al cuidado de los fondos públicos". Auditoría General de la Nación.

- Dorna, G. y Ruffo, H. (2017). "Evaluación de Impacto. Proyecto de Mejora Integral del Ferrocarril Gral. Roca, Ramal Plaza Constitución - La Plata". Informe interno.

- ENMODO (2010). "Encuesta de Movilidad Domiciliaria 2009-2010: Movilidad en el Área Metropolitana de Buenos Aires. Resultados de la encuesta origen-destino". Secretaría de 
Transporte de la Nación. Disponible en línea: http://uecmovilidad.gob.ar/encuesta-de-movilidaddomiciliaria-2009-2010-movilidad-en-el-area-metropolitana-de-buenos-aires/

- Evans, A. W., \& Morrison, A. D. (1997). "Incorporating accident risk and disruption in economic models of public transport". Journal of Transport Economics and Policy, 117-146.

- Firpo, S., \& Possebom, V. (2016). "Synthetic control estimator: A generalized inference procedure and confidence sets". Mimeo.

- FitzRoy, F. R., \& Smith, I. (1998). "Passenger rail demand in 14 western European countries: a comparative time series study". International Journal of Transport Economics/Rivista internazionale di economia dei trasporti, 299-312.

- Fleitas, D. M., (2007). "Accidentes de tránsito en Argentina”. Asociación para Políticas Públicas.

- Fremeth A., Holburn G., Richter B. (2016). "Bridging Qualitative and Quantitative Methods in Organizational Research: Applications of Synthetic Control Methodology in the U.S. Automobile Industry". Organization Science.

- González, N. (2017). "El error humano en el análisis de accidentes ferroviarios". Revista de Ciencias Sociales (Cr), 4(158), 149-165.

- Instituto Geográfico Nacional (IGN). "SIG 250: Set de archivos shapefile para utilizar en un Sistema de Información Geográfica”. Red Ferroviaria.

- Ito, H., \& Lee, D. (2005). "Assessing the impact of the September 11 terrorist attacks on US airline demand". Journal of Economics and Business, 57(1), 75-95.

- Mohring, H. (1972). "Optimization and scale economies in urban bus transportation". The American Economic Review, 62(4), 591-604.

- Müller, A. (2012). "La tragedia de Once y el ferrocarril". Nota Breve No10. CESPA.

- Newstead, S., \& Cameron, M. H. (2003). "Evaluation of the crash effects of the Queensland speed camera program" (No. 204). Monash University Accident Research Centre.

- Owen, A. D., \& Phillips, G. D. A. (1987). "The characteristics of railway passenger demand. An econometric investigation". Journal of Transport Economics and Policy, 231-253.

- Pirota, M. D. (2009). "Los accidentes ferroviarios en la jurisprudencia". Revista de responsabilidad civil y seguros: publicación mensual de doctrina, jurisprudencia y legislación, 11(12), 55-65.

- Preston, J., \& Robins, D. (2013). "Evaluating the long term impacts of transport policy: The case of passenger rail privatisation". Research in Transportation Economics, 39(1), 14-20.

- Resolución N 1244. "Operadora Ferroviaria Sociedad del Estado. Acuerdo de Operación de los Servicios Ferroviarios Urbanos de Pasajeros - Grupo de servicios 1 y 2 Líneas Sarmiento - Mitre y sus Addendas. Rescisión". Ministerio del Interior y Transporte. Buenos Aires, Argentina. 24 de octubre de 2013.

- Sartori, J. J. P. (2003). "Estimación de elasticidades de demanda para el transporte urbano de pasajeros de la ciudad de Córdoba (Argentina)". Anales de la XXXVIII Reunión de la Asociación Argentina de Economía Política.

- UNE-EN 13816. "Transporte. Logística y servicios. Transporte público de pasajeros. Definición de la calidad del servicio, objetivos y mediciones". Asociación Española de Normalización y Certificación (AENOR). Madrid, España. Enero de 2003.

- UNE-EN 15140. "Transporte público de pasajeros. Requisitos básicos y recomendaciones para los sistemas de medición de la calidad del servicio producida". Asociación Española de Normalización y Certificación (AENOR). Madrid, España. Octubre de 2006.

- Wang, K., Xia, W., Zhang, A., \& Zhang, Q. (2018). "Effects of train speed on airline demand and price: Theory and empirical evidence from a natural experiment". Transportation Research Part B: Methodological, 114, 99-130.

- Wardman, M. (1994). "Forecasting the impact of service quality changes on the demand for inter-urban rail travel". Journal of Transport Economics and Policy, 287-306.

- Wardman, M. (2006). "Demand for rail travel and the effects of external factors". Transportation Research Part E: Logistics and Transportation Review, 42(3), 129-148. 
- Webster, F. V., \& Bly, P. H. (1982). "The demand for public transport. Part II. Supply and demand factors of public transport". Transport Reviews, 2(1), 23-46.

- Wei, F., Chen, J., \& Zhang, L. (2017). "Demand shocks, airline pricing, and high-speed rail substitution: Evidence from the Chinese market". Journal of Transport Economics and Policy (JTEP), 51(4), 266-289.

- Zotova, I. (2017). "Post-crash airline pricing: A case study of Alaska Airlines Flight 261". Economics of transportation, 10, 18-22. 
7. ANEXOS

\subsection{Anexo 1}

Figura A1. Mapa de Buenos Aires con líneas de ferrocarril

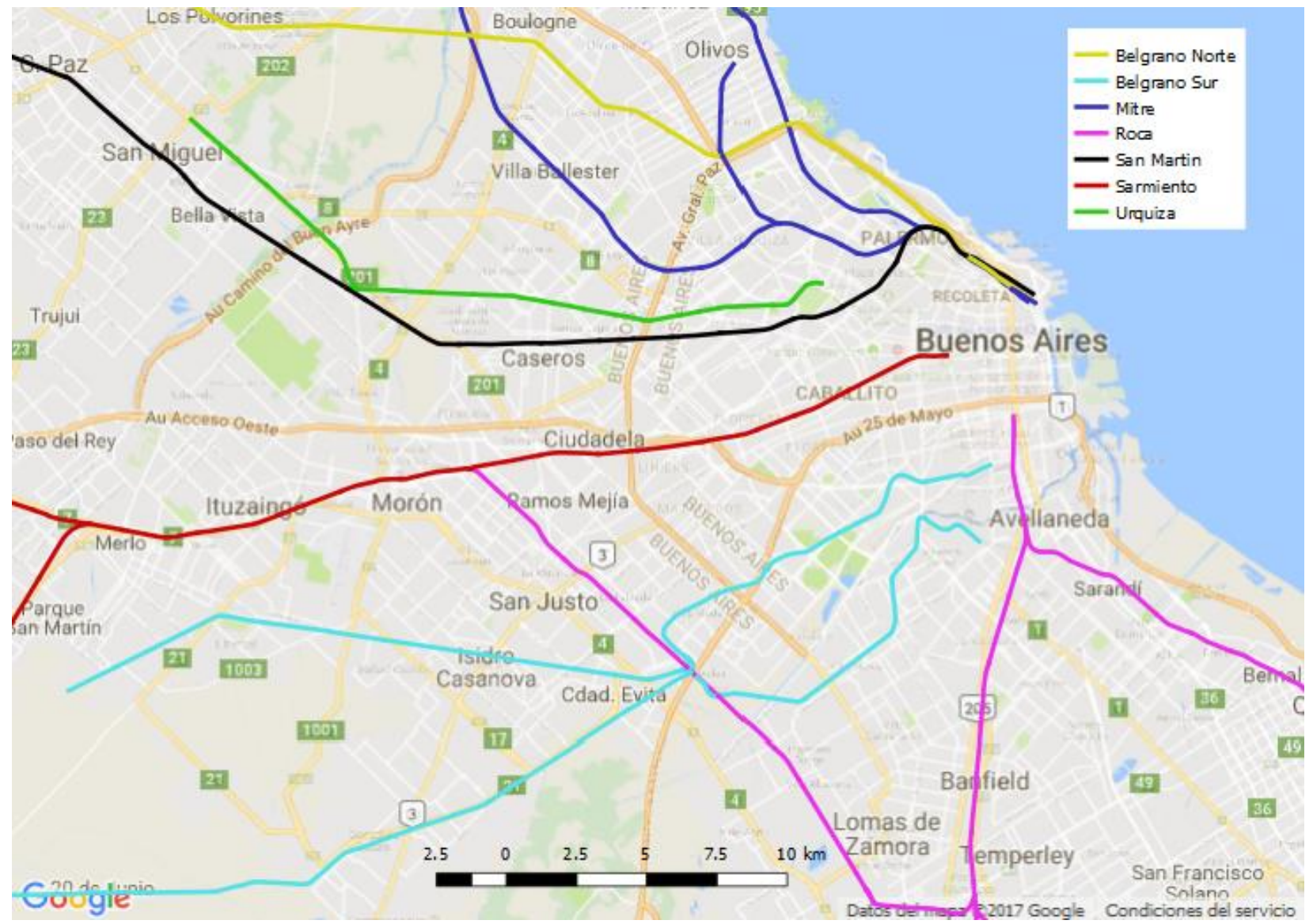

Fuente: Elaboración propia en base a datos del Instituto Geográfico Nacional 


\subsection{Anexo 2}

Gráfico A2. Boletos vendidos por tren corrido

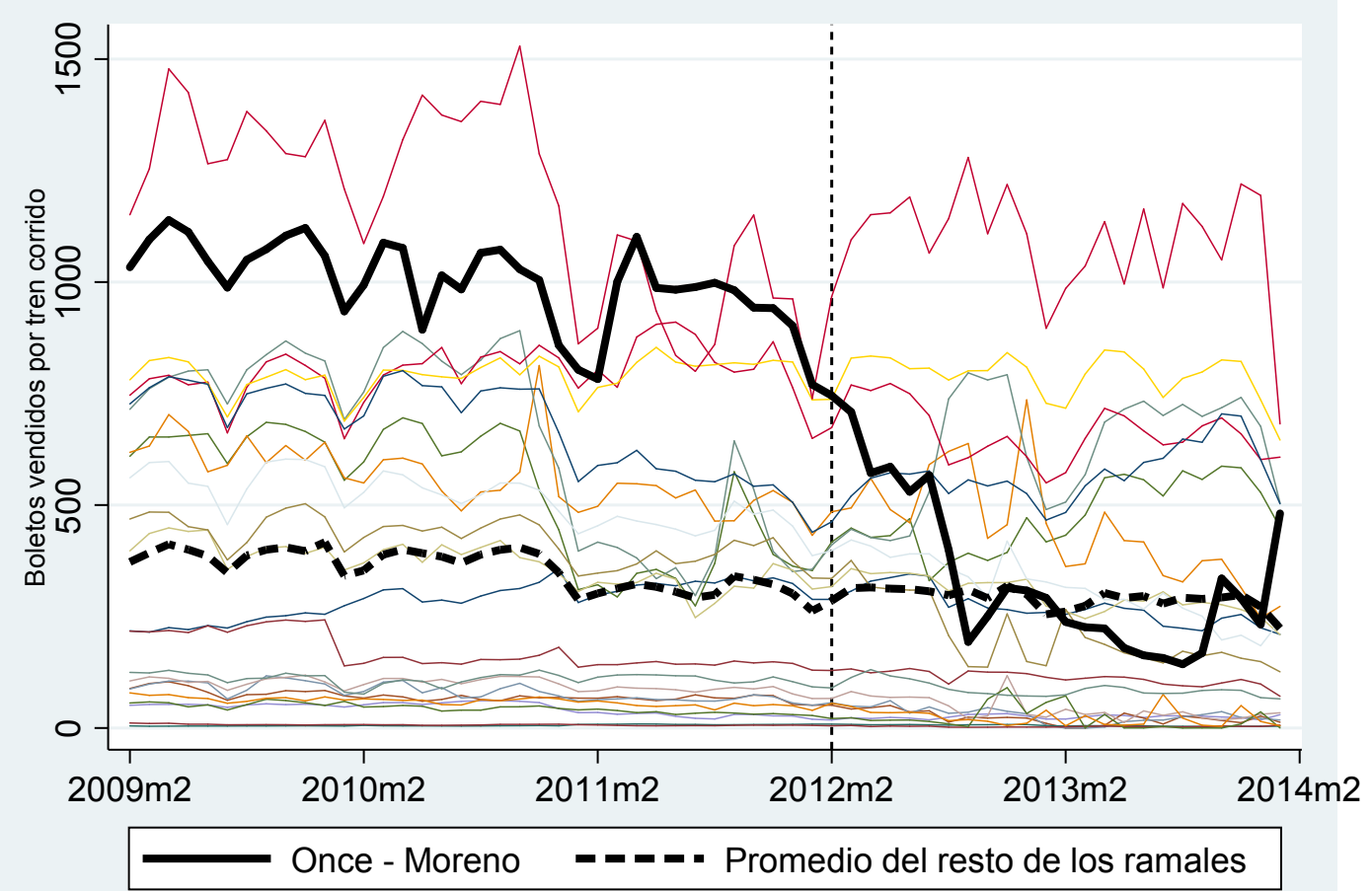

Fuente: elaboración propia en base a datos de la CNRT 


\subsection{Anexo 3}

Tabla A3. Matriz V: ponderadores de los predictores

\begin{tabular}{|lcr|}
\hline Variables & CS1 & CS2 \\
\hline Log. de los km recorridos & $31 \%$ & $19 \%$ \\
\hline Velocidad promedio & $7 \%$ & $14 \%$ \\
\hline Tasa de trenes corridos & $6 \%$ & $23 \%$ \\
\hline Tasa de trenes puntuales & $19 \%$ & $17 \%$ \\
\hline Cantidad de estaciones & $0,11 \%$ & $15 \%$ \\
\hline Trenes eléctricos & $0,004 \%$ & $0,06 \%$ \\
\hline Índice de boletos por tren corrido (mes anterior) & $34 \%$ & $8 \%$ \\
\hline Índice de boletos por tren corrido (año anterior) & $4 \%$ & $3 \%$ \\
\hline
\end{tabular}

Fuente: Elaboración propia en base a datos de la CNRT 


\subsection{Anexo 4}

Gráfico A4.1 Test placebo in-time: utilizando CS1

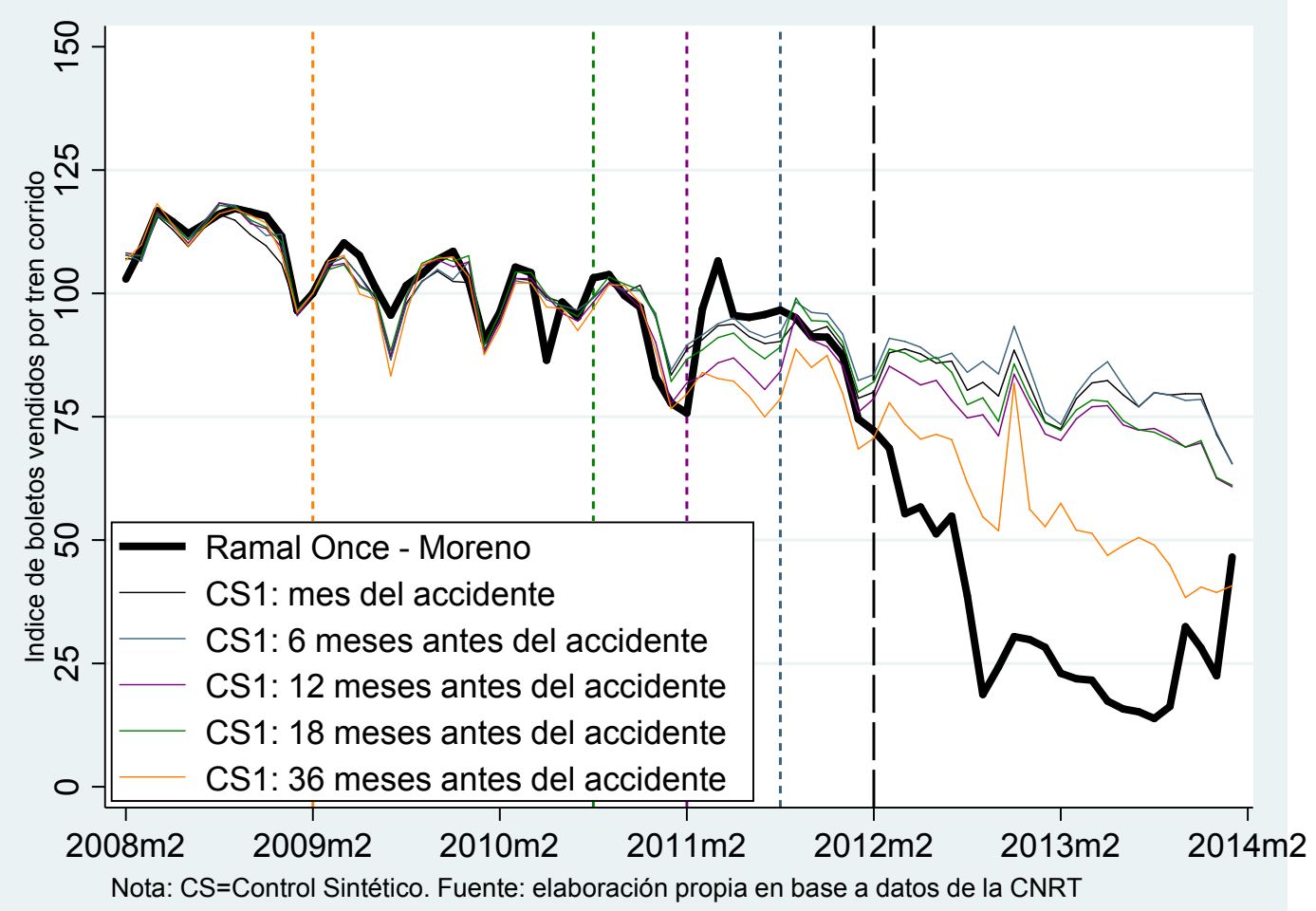

Gráfico A4.2. Test placebo in-time: utilizando CS2

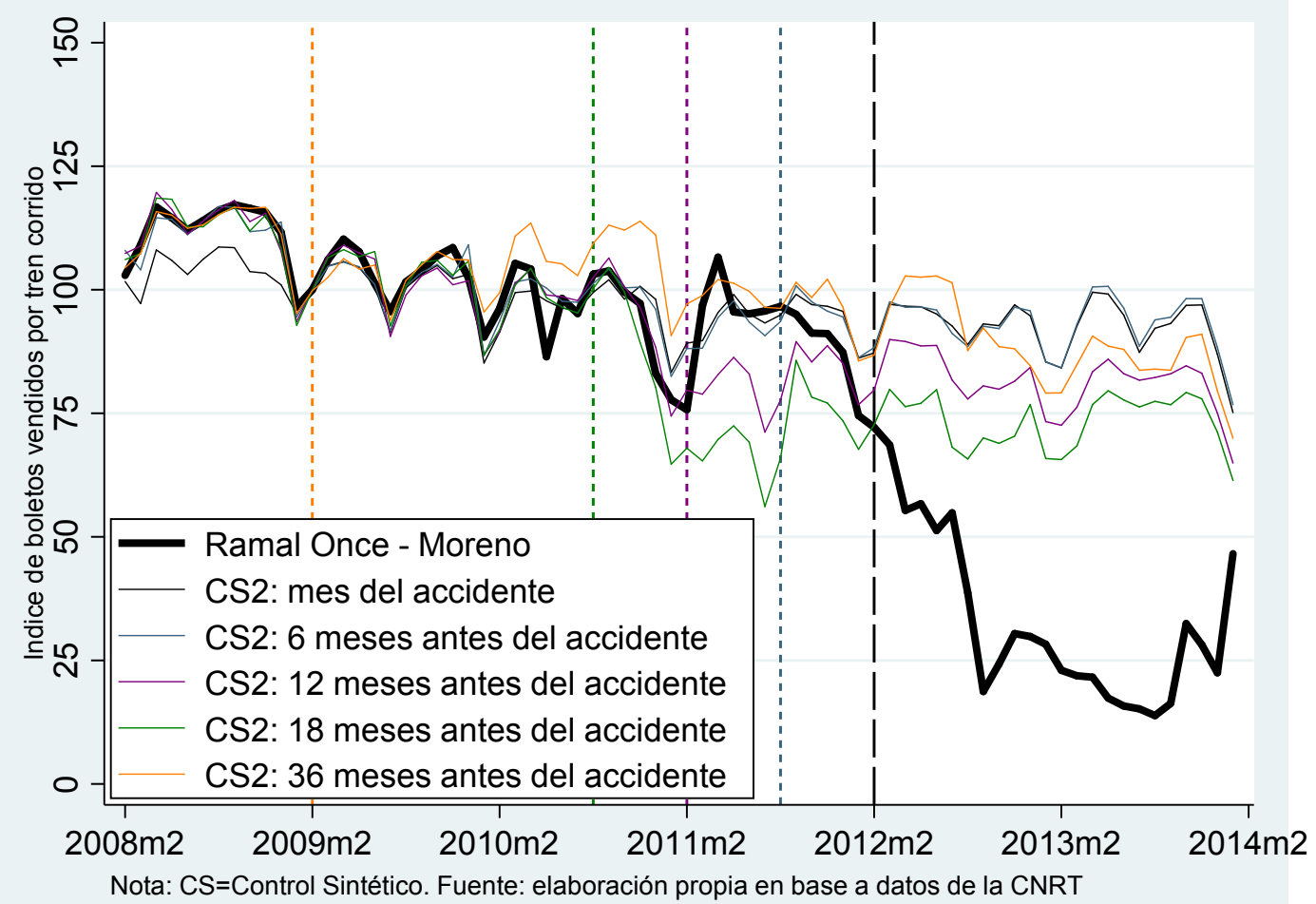




\subsection{Anexo 5}

Gráfico A5.1. Distribución del ratio de RMSPE: CS1

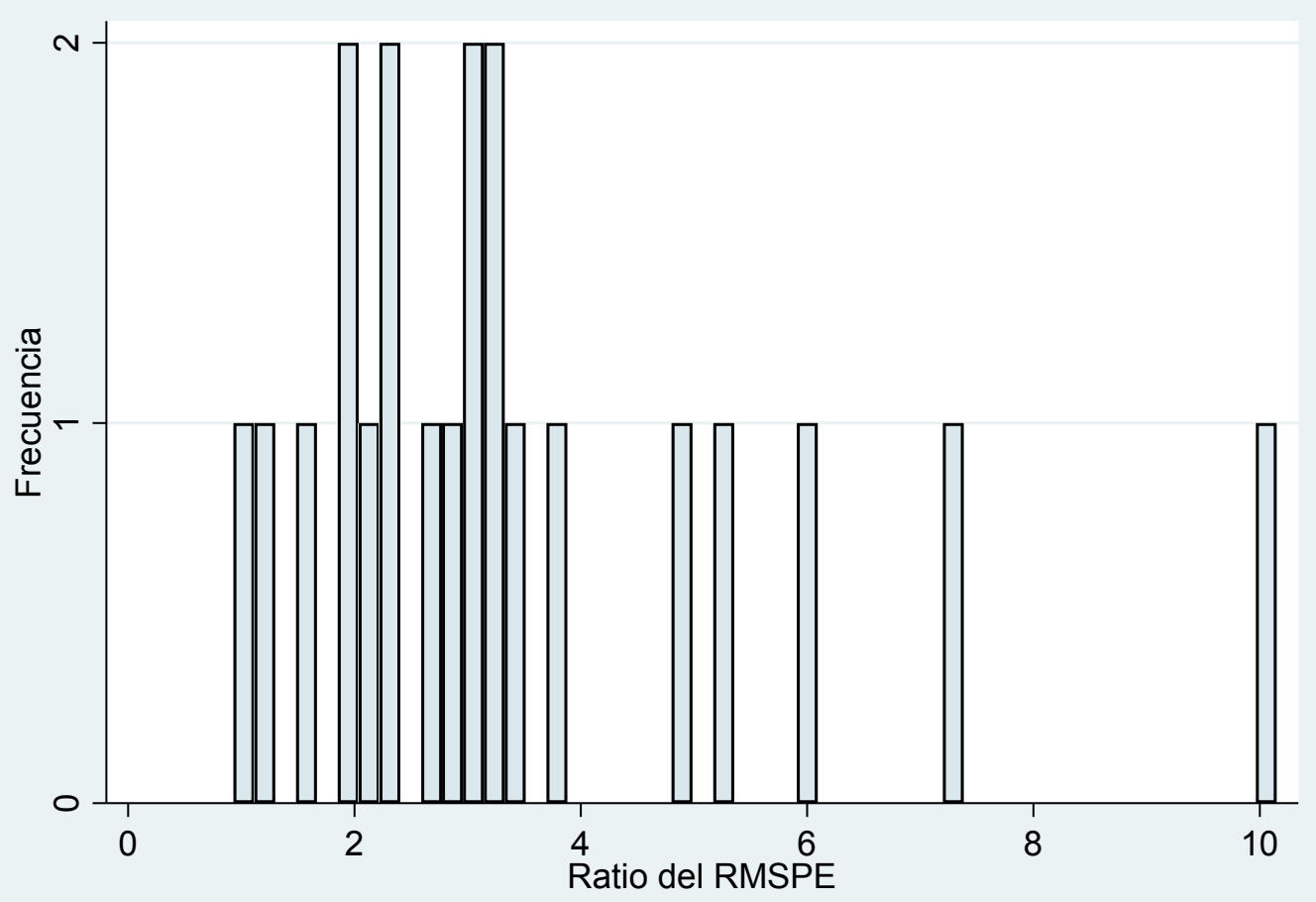

Fuente: elaboración propia en base a datos de la CNRT

Gráfico A5.2 Distribución del ratio de RMSPE: CS2

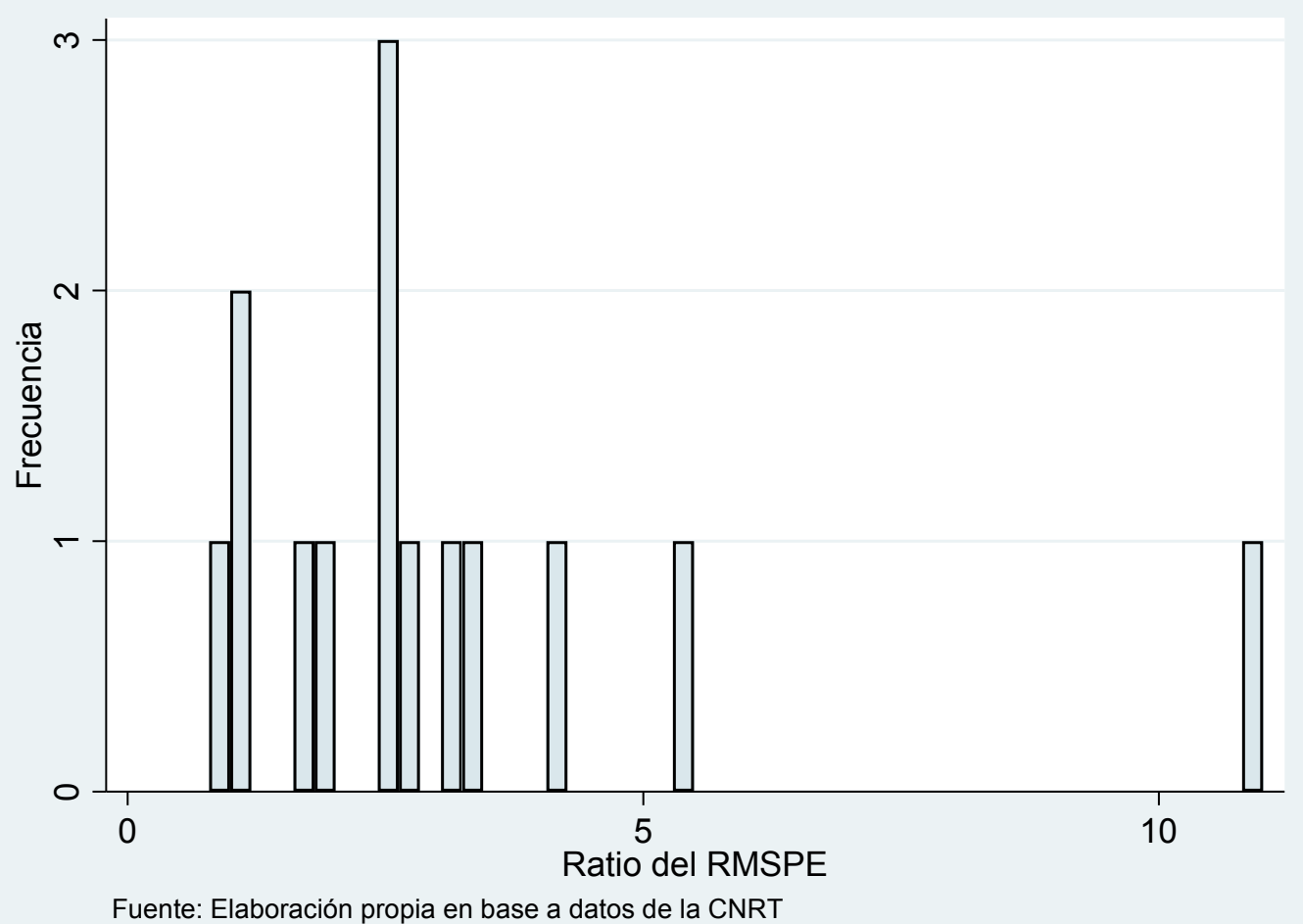




\subsection{Anexo 6}

En este apéndice se analiza el efecto del accidente de Once sobre la demanda de la línea de subte A.

Como se resaltó en la sección 2.3, por cuestiones de distancia entre las estaciones de subtes y las del ramal afectado, no se esperaría un efecto sobre la demanda de subtes a partir del accidente, con la excepción de la línea de subte $A$, ya que comparten un trayecto de sus recorridos, tal como se puede distinguir en la siguiente figura:

Figura A6 Mapa de subtes y ramal Once - Moreno

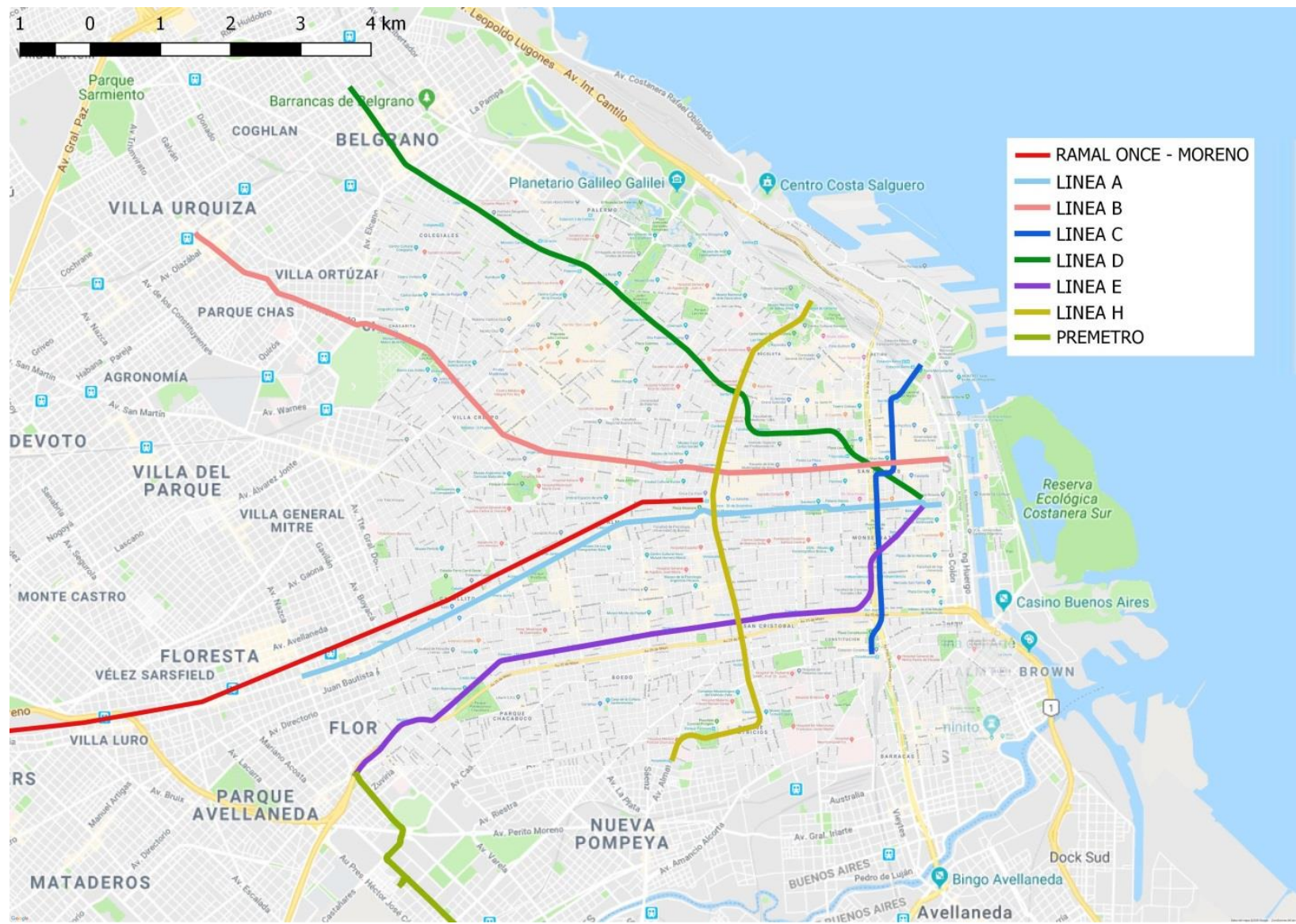

Fuente: Elaboración propia en base a datos del Instituto Geográfico Nacional

Esta característica implica que pueda haber un efecto substitución y complementariedad entre el ramal Once - Moreno y la línea de subte A: el efecto sustitución podría suceder en esos $7 \mathrm{~km}$ de trayecto que ambas líneas tienen en común ${ }^{29}$, mientras que el efecto complementariedad se debe a que existen usuarios que combinan ambos modos de transporte en sus viajes ${ }^{30}$.

Esto implica que el accidente de Once podría afectar positivamente la demanda de la línea A, en caso de que usuarios del ramal Once - Moreno reemplacen dicho modo de transporte por el

${ }^{29}$ Según la ENMODO (2010), en la Región Metropolitana de Buenos Aires el 1,4\% de los usuarios del tren Sarmiento hacen su recorrido entre dos estaciones de dicho trayecto, y podrían substituirlo por el subte $A$.

30 Según la ENMODO (2010), en la Región Metropolitana de Buenos Aires el 12\% de los usuarios del tren Sarmiento utilizan también el subte A en sus recorridos. 
subte, y negativamente en caso de que dejen de utilizar la combinación tren y subte, por ejemplo utilizando un único colectivo ${ }^{31}$.

A continuación se presenta el ejercicio de utilizar la estrategia control sintético para estimar el efecto de la tragedia de once sobre la evolución en la venta de boletos de la línea de subte $A$, utilizando como unidades de controle el resto de líneas de subte:

\section{Gráfico A6 Control sintético: Subte A}

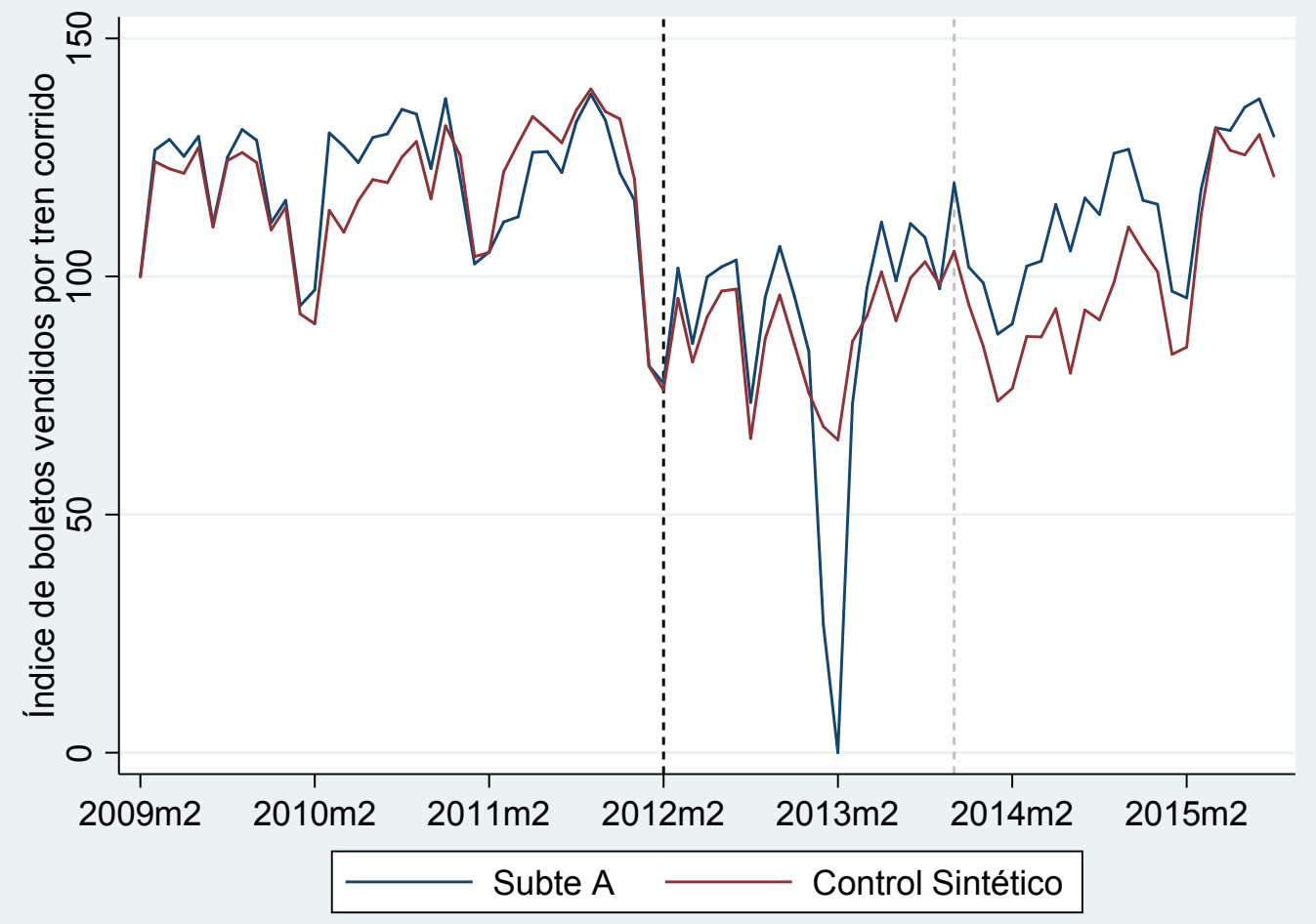

Fuente: Elaboración propia en base a datos de la CNRT.

Como puede apreciarse en el gráfico, si bien existe una brecha positiva entre la evolución de venta de boletos de la línea A y su respectivo control sintético, la cual resulta de $5 \mathrm{pp}^{32}$ en promedio para los dos años posteriores al accidente, la misma no resulta de gran magnitud en comparación con el 1,5pp de diferencia que existía antes de la tragedia.

\footnotetext{
${ }^{31}$ Este efecto negativo se reduciría en caso de que los usuarios del ramal Once - Moreno reemplacen el tren por un colectivo, pero continúen utilizando el subte $\mathrm{A}$.

32 No se considera el mes de febrero de 2013, ya que la línea A permaneció cerrada luego del traspaso del servicio al Gobierno de la Ciudad de Buenos Aires.
} 


\subsection{Anexo 7}

Figura A7. Tapas de diarios

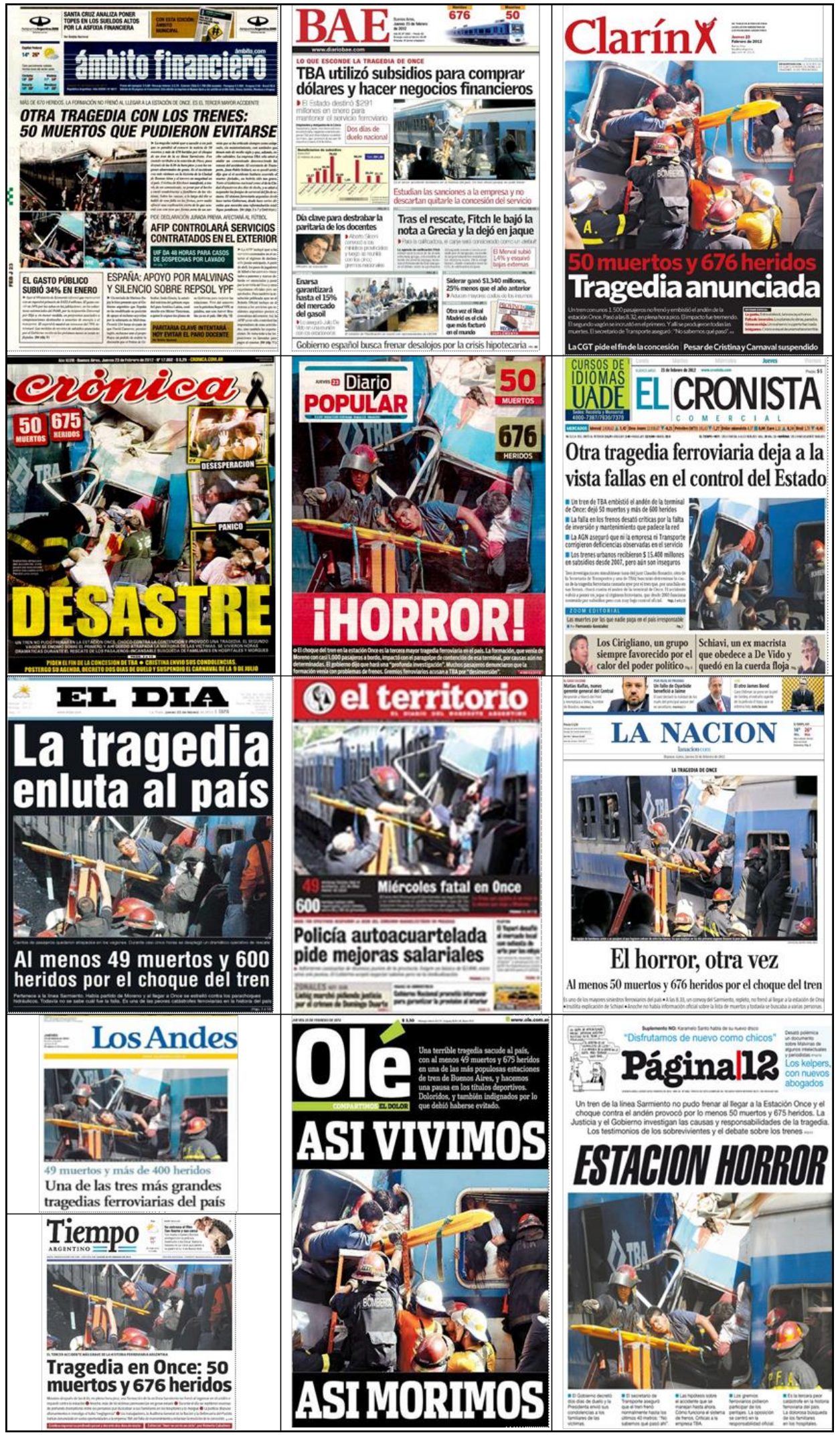

Fuente: Elaboración propia en base a tapa de diarios 